\title{
Distinct methane-driven biogeochemical regimes in Arctic seafloor gas hydrate mounds
}

\section{Scott Klasek}

University of Wyoming

Wei-Li Hong

Stockholm University https://orcid.org/0000-0002-7247-1827

Marta Torres

Oregon State University

\section{Stella Ross}

Oregon State University

Katelyn Hostetler

Oregon State University

\section{Alexey Portnov}

The Ohio State University

Friederike Grundger

Arctic Research Centre

Frederick Colwell ( $\nabla$ rick.colwell@oregonstate.edu )

Oregon State University

\section{Article}

Keywords: Arctic seafloor, methane escape, gas hydrate mounds

Posted Date: November 23rd, 2020

DOI: https://doi.org/10.21203/rs.3.rs-93738/v1

License: (c) (i) This work is licensed under a Creative Commons Attribution 4.0 International License.

Read Full License 


\section{Abstract}

Archaea mediating anaerobic methane oxidation are key in preventing methane produced in marine sediments from reaching the hydrosphere; however, a complete understanding of how microbial communities in natural settings respond to changes in methane flux remains largely uncharacterized. We investigate microbial communities in gas hydrate-bearing seafloor mounds at Storfjordrenna, offshore Svalbard in the high Arctic, where distinct methane flux regimes ranging from steady-state dynamics, recent increase in subsurface diffusive flux, and gas seepage were identified. Populations of anaerobic methanotrophs and sulfate-reducing bacteria were highest at the seep site, while a recent increase in methane influx was associated with decreased community diversity. Despite high methane fluxes and methanotroph doubling times estimated at 5-9 months, microbial community responses were largely synchronous with the advancement of methane into shallower sediment horizons. Together, these provide a framework for interpreting subseafloor microbial responses to methane escape in a changing Arctic.

\section{Introduction}

Microbially-generated methane in marine sediments has been estimated at $1013-1014 \mathrm{~g}$ per year1. Microbial anaerobic methane oxidation (AOM) is responsible for consuming the majority of this methane-up to $90 \% 1$-before it can escape to the hydrosphere. This globally-widespread2 microbial methane filter consists of very slow-growing3,4, currently uncultured clades of anaerobic methanotrophic archaea (ANME) and often-symbiotic sulfate-reducing bacteria (SRB) that thrive at sulfate-methane transitions (SMTs), sediment depths where methane is oxidized with sulfate (SR-AOM) 5 . In contrast to the large areas where SMTs occur within the sediment, at discrete locations of active methane gas release, such as pockmarks and mud volcanoes, over $90 \%$ of the methane can escape the microbial filter, even though AOM rates at these sites are considerable (several nmol cm-3 d-1)6. Methane release from the Arctic seafloor has received significant attention over the past two decades7. Seafloor permafrost methane venting to the atmosphere has been documented along a wide portion of the East Siberian Margin8, the South Kara Sea shelf9, and the upper slope of the Beaufort Sea10. Extensive geophysical surveys have characterized thousands of fault-associated seeps below warming waters along the West Spitsbergen (Svalbard) margin11,12; numerical modeling and U/Th dates from authigenic carbonates revealed that seepage has persisted here for hundreds to thousands of years13,14. The Storfjordrenna trough mouth fan, $\sim 50 \mathrm{~km}$ south of Svalbard, hosts gas hydrate-bearing mounds (GHMs) on the seafloor that are morphologically similar to those described in the Beaufort15 and Kara16 Seas (Fig. 1A). These GHMs lie below water depths of 370-390 meters, which approach the upper limit of gas hydrate stability in this area17. Gas leakage was observed at four of five GHMs, which are thought to have formed from hydrate accumulation and methane gas overpressure following glacial retreat17. Microbial community responses to subsurface methane release, whether driven by tectonic18, climate19 and/or oceanographic20 forcings, are important to constrain because they support macrofaunal communities 21 of ecological and economic importance22. However, how these microbial communities respond to 
changes in methane release over time in Arctic cold seeps remains largely uncharacterized. Such knowledge is of immediate importance as environmental changes, from either natural or anthropogenic causes, could potentially result in a sudden increase of methane flux. In the Arctic Ocean, abrupt release of methane from gas hydrate dissolution in the central Barents Sea has been hypothesized23, while methane release from the Deepwater Horizon oil spill into deep Gulf of Mexico waters was correlated with the growth of aerobic methane-oxidizing Gammaproteobacteria and oxygen drawdown24. Sediment microbial community responses to fluctuating methane regimes have been characterized at mud volcanoes25,26, and methane has recently been found to shape community structure at Storfjordrenna GHMs27. However, a dynamic understanding of how microbial activity may mitigate methane release in this habitat is currently unknown. Changes in concentration gradients of porewater sulfate in marine sediments have been used to constrain the timing of subaqueous landslides 28 and to indicate irrigation (through bioturbation or ascending gas bubbles29) or migration of upwards-diffusing methane14. Under steady-state conditions with a constant methane flux, sulfate decreases linearly with depth until the SMT is reached30 (Fig. 1B). At locations experiencing increases in methane flux, sulfate deviates from the linear profile, showing an abrupt decrease to $<1 \mathrm{mM}$ within a small depth range (Fig. 1C). The sulfate reduction (SR) zone thins in response to methane advancement into shallower layers, which stimulates AOM within them. Reactive transport modeling of the deviation from linearity in porewater sulfate profiles (Fig. 1D) can be used to estimate how long ago methane began to diffuse into shallower sediment zones, provided that other phenomena (advection, seawater irrigation, bioturbation, or mass transport deposits) are minimized or constrained14,28. Other geochemical signatures, combined with observations of free gas and gas hydrates, support a model where episodic methane emission occurs in pulses, with distinctive pre- and post-active stages31. In this work, we constrain temporal responses of microbial communities as methane migrates upwardly towards shallow sediment horizons. Using samples and data from Storfjordrenna GHMs, where varying regimes of methane transport are evident, we employ interdisciplinary geochemical, numerical, and microbiological approaches. We report shifts in AOM rates, ANME/SRB abundances, and microbial communities concomitant with recent changes in methane flux, showing a tightly-coupled microbial response to intensifying subseafloor methane fluxes.

\section{Results}

\section{Identification of distinct regimes of methane transport.}

To investigate microbial communities across regimes of methane dynamics in Storfjordrenna GHMs, we collected sediment cores from GHMs where seepage was either observed or absent (Fig. 1, Table S1). GHM3 and GHM4 show persistent hydroacoustic gas flares over multi-year surveys and thus represent active seepage ${ }^{17}$. Here, ascending free gas is the dominant carrier of methane, with limited movement in porewater ${ }^{31}$. In contrast, abundant trace elements in porewaters from GHM5 point towards upward fluid advection, which may have followed prior seepage activity ${ }^{31}$. Geochemical data, numerical modeling results, microbial communities, and functional gene abundance data are presented for these regimes in figures 2 through 4, grouped according to different methane transport scenarios. First, we present four 
cores from areas exhibiting steady-state methane-sulfate dynamics (i.e. no temporal changes in methane flux), with gravity core (GC) 1048 representing a low methane flux case from a non-GHM area (Fig. 2). Increasing methane fluxes in areas at GHM3 and GHM4 have allowed methane to diffuse into shallower sediment horizons, and sulfate profiles at these sites document the departure from a steady-state condition (Fig. 3). Finally, at an active seep site, downcore changes from a push core precisely taken by a remote-operated vehicle (ROV) from GHM3 capture biogeochemical signatures that reflect high methane flux, gas bubble emission, and advective delivery of seawater into the upper sediment column (Fig. 4). Corresponding data are provided in supplementary materials.

\section{Field descriptions and general patterns.}

Black-colored glaciomarine sediments were recovered in all cores, reflecting the precipitation of iron sulfide minerals resulting from high rates of sulfide production ${ }^{32}$. Authigenic carbonate nodules were retrieved in several cores, and chunks of gas hydrates several $\mathrm{cm}$ in diameter were observed between 40$50 \mathrm{~cm}$ below seafloor in a replicate of push core (PC) 1029. Cores PC1029 and GC1081 were taken from areas of gas seepage indicated by the white polygons in Fig. 1. Core recovery lengths ranging from 102 to $335 \mathrm{~cm}$ captured SMTs in all cores except for PC1029 (Table S1). Across all cores, alkalinity profiles that contrast with the decline in sulfate provide further support of AOM as the dominant sink for sulfate (Figs. 2A, 3A, 4A). In situ methane values are probably higher than those reported, as gas samples were taken from cores at atmospheric pressure. No bubbles or moussy sediment texture was observed in the recovered cores, discounting the possibility of degassing upon core retrieval.

Bacterial and archaeal 16S rRNA gene sequencing recovered 3.12 million sequences and 16,470 amplicon sequence variants (ASVs) after contaminants were removed. Bubble plots (Figs. 2C, 3C, 4B, left panels) show the fifteen most abundant taxonomic classes in the dataset, each of which individually constitute $1 \%$ or more of the total sequences, and combined account for $83.6 \%$ of reads in the dataset. The three most common ASVs, which alone comprise $22.2 \%$ of all sequences, belong to the class JS1 (phylum Atribacteria) which are thought to ferment organic matter ${ }^{33}$. Two other dominant classes, Deltaproteobacteria and Methanomicrobia, are subdivided into genera of sulfate-reducing bacteria (SRB) and anaerobic methanotrophs (ANME), respectively (Figs. 2C, 3C, 4B, right panels). Respectively, ANME and SRB make up $10 \%$ and $12 \%$ of total sequences in this dataset. ANME are most dominant at or near SMTs, but correlate most strongly with peak AOM rates derived from numerical modeling. Two clades of

sulfate-reducing bacteria that commonly associate with ANME at seeps, SEEP-SRB1 and SEEP-SRB2 ${ }^{34,35}$, share similar distribution patterns. Droplet digital PCR counts of the methane-fixing methyl-coenzyme reductase gene $m c r A$ and dissimilatory sulfate reduction gene $d s r A B$ span several orders of magnitude across cores and depths (Figs. 2D, 3D, 4C). Methods are detailed at the end of the manuscript.

\section{Regimes of methane dynamics defined by geochemical and microbial data.}

Steady-state biogeochemical equilibrium. 
Three gravity cores from GHM5 (and one nearby, in the case of GC1048) showed linear decreases in sulfate, with methane present only below the SMT (Fig. 2A). We classify these sites as being at steadystate with respect to sulfate-methane dynamics, and hereafter refer to them as steady-state cores. Sulfide profiles mirror the shape of the alkalinity curves, peaking at SMT depths. In addition, macroscopic SMTassociated mucoid biofilms consisting predominantly of ANME- ${ }^{36}$, were observed in split cores at 63 and $68 \mathrm{~cm}$ in GC1070 and at $305 \mathrm{~cm}$ in GC1048 (Fig. 2A). Modeled AOM rates peak at or several cm above the SMT, and show maxima of $<20 \mathrm{nmol} \mathrm{cm}^{-3} \mathrm{~d}^{-1}$ (Fig. 2B); depth-integrated fluxes are below 1 mol $\mathrm{m}^{-2} \mathrm{yr}^{-1}$ (Fig. S1). Though both ANME-1 subclades are nearly equally abundant in all samples from this study, ANME-1a are more dominant in steady-state cores (Fig. 2C). In GC1068, highest mcrA counts are seen at the peak $A O M$ depth, though gene abundance profiles otherwise display considerable variability and $d s r A B$ counts are typically low, between $10^{4}-10^{5}$ copies per gram bulk sediment (Fig. 2D).

Increasing methane flux.

GC1045 was sampled from the southern margin of GHM3, and GC1081 from the center of GHM4 (Fig. 1). Sulfate profiles from these cores show concave-up curvature, indicating that the methane-sulfate dynamics are not at steady-state, but likely reflect a recent increase in methane flux ${ }^{14}$ (Fig. 3A). Porewater sulfate profiles show a rapid decrease in concentration down core and SMTs are well established. As estimated by our reduced modeling approach, total methane fluxes throughout these two cores have increased over the past two decades (Table S2). Modeling scenarios were constructed on a prior dataset of several porewater species from Storfjordrenna in an attempt to account for other processes, but only a scenario applying contrasts in methane flux adequately fit these data ${ }^{14}$. No fractures, mass transport deposits, porosity changes, or evidence of bioturbation were found in the gravity cores analyzed, and a buildup of ammonium to $60 \mu \mathrm{M}$ (data not shown) in the first $50 \mathrm{~cm}$ of GC1045 allows us to discount the possibility of oxic bottom water intrusion. These cores experiencing increases in methane flux were initially assumed to be at steady-state before methane migrated upwards through the sediment column. Fluxes are integrated from all modeled AOM rates assuming AOM as the only sink for sulfate. Ammonium concentrations from GC1045 do not exceed $200 \mu \mathrm{M}$, and assuming a C:N ratio of 6.1, a maximum of only $0.61 \mathrm{mM}$ of sulfate would be consumed by organoclastic sulfate reduction. Following these constraints, our model estimates peak AOM rates of $\sim 200 \mathrm{nmol} \mathrm{cm}^{-3} \mathrm{~d}^{-1}$, which are an order of magnitude higher than those derived for steady-state cores (Fig. 3B). At the time of sampling, peak AOM rates were positioned at or up to $20 \mathrm{~cm}$ above the SMT depth (Fig. 3B), though running the model backwards or forward in time reveals an upward migration at a linear rate of $10 \mathrm{~cm}$ per year (Fig. 3B, Table S2). A more thorough description of this modeling approach is provided in the Supplemental Information.

In contrast to the steady-state cores, the dominance of Deltaproteobacteria, JS1, and Methanomicrobia are more apparent in GC1045 and GC1081, and ANME-1b are the most abundant ANME genus (Fig. 3C). Counts of $m c r A$ are higher than in steady-state samples, reaching maxima around $10^{7}$ copies per gram at SMTs in both cores (Fig. 3D). Though $d s r A B$ counts are also comparable at these SMTs, higher $d s r A B$ 
abundances at shallower depths in GC1045 likely reflect a larger or more diverse sulfate-reducing community than in GC1081.

Active methane seepage.

PC1029 was recovered from an established patch of frenulate siboglinid tubeworms (Oligobrachia sp. CPL clade, Fig. S2) whose chemosynthetic lifestypes are supported by sulfide generated from SR-AOM at sites with high methane discharge ${ }^{21,37,38}$. Observations of vigorous gas bubbling and recovery of gas hydrate support the inference that the site was experiencing high methane seepage at the time of sampling. Sulfate concentrations at near-seawater values up to $10 \mathrm{~cm}$ below seafloor at PC1029 (Fig. 4A) may be attributed to seawater infiltration (siboglinid bioirrigation or bubble-driven convection) and/or sulfide oxidation from bacterial symbionts ${ }^{39}$. Further downcore, the incomplete drawdown of sulfate and high methane concentrations suggest that sulfate-coupled AOM is an ongoing process, pointing towards a high methane flux at the center of GHM3. As processes other than sulfate diffusion from seawater are not accounted for in our model parameterization, we are unable to precisely calculate AOM rates from PC1029. Our rough estimation of the AOM rate based on the part of the sulfate profile with the greatest concentration gradient (10-15 cmbsf) yields a peak AOM rate on the order of $10^{3} \mathrm{nmol} \mathrm{cm}^{-3} \mathrm{~d}^{-1}$. This rate estimate would be increased significantly by accounting for siboglinid-driven pumping of bottom seawater sulfate, or sulfide reoxidation mediated by their endosymbionts. Nevertheless, this estimated AOM rate is an order of magnitude higher than the rates calculated for cores experiencing increases in methane flux shown in Figure 3B.

Microbial communities from PC1029 show higher percent abundances of several classes, notably Bacteroidia and Gammaproteobacteria, than in cores representing other regimes of methane dynamics (Fig. 4B). ANME-2 are present at 1-3 cm in PC1029, but ANME-1b are dominant at depths with lower sulfate concentrations (Fig. 4B). ANME-1a are nearly absent, agreeing with recent observations from this seep location ${ }^{27}$ and contrasting the two other regimes. Near-equal abundances of SEEP-SRB1 and SEEPSRB2 at PC1029 are reminiscent of GC1081, the other core from a seep site (Figs. 4B, 3C). Highest $m c r A$ concentrations, exceeding $10^{8}$ copies per gram bulk sediment, were recovered in PC1029, even in depths with high sulfate, low methane, and low alkalinity (Fig. 4C); these values are comparable to ANME cell

counts reported from other seep sites ${ }^{25,40}$. Counts of dsrAB were over an order of magnitude lower than $m c r A$ throughout the core, but still higher than in nearly all other samples from different regimes.

\section{Response times of ANME and SRB to methane pulses as inferred from porewater modeling.}

In areas experiencing increases in methane flux, modeled AOM peaks migrate upward with time (Fig. 3B). Different depths, and thus microbial communities inhabiting them, can be assigned by the time they experienced (or are expected to experience) this upward-moving peak in AOM. At GC1045 and GC1081, AOM fronts migrate upward at roughly $10 \mathrm{~cm}$ per year (Fig. 3B, Table S2); thus GC1045 communities from $66,76,86$, and $110 \mathrm{~cm}$ depths respectively correspond to AOM peaks at the time of collection, and 
one, two, and over four years before. Highest relative abundances of SEEP-SRB1 and total ANME, as well as highest concentrations of $m c r A$, are seen in the community sampled at $76 \mathrm{~cm}$ (Fig. 3C, D), suggesting these taxa dominate microbial communities after about a year following methane migration into this sediment horizon. In contrast, ANME-1b are highest in the community from $66 \mathrm{~cm}$, which may reflect a quicker growth or a preference for lower methane concentrations compared to ANME-1a. In the timespan from one to four years after the AOM pulse has passed through, mcrA abundances decreased by nearly three orders of magnitude, but $d s r A B$ by less than one. After four years, the AOM pulse moves onward and microbial communities are starved of sulfate, ANME and SRB populations respectively decrease from 46 to $1.1 \%$ and 22 to $1.8 \%$ of the total community.

GC1081 communities from 56.5, 69, and $86 \mathrm{~cm}$ correspond to maximum AOM rates from the time of sampling, one and a half, and three years ago, respectively, while the community at $49 \mathrm{~cm}$ is associated with high (but not yet peaking) AOM rates (Fig. 3B). In contrast to communities from GC1045, ANME percent abundances do not decrease as quickly, and SEEP-SRB1 increases with depth (Fig. 3C). A similar trend of ANME-1b growth preceding ANME-1a is noticed, but surprisingly ANME-1b are present in high relative abundance at $24 \mathrm{~cm}$, where $A O M$ rates are not expected to be significant until two years after sampling. Concentrations of $m c r A$ and $d s r A B$ both roughly correspond to the present-day AOM pulse, showing no lag time with respect to methane influx (Fig. 3D). Across samples for which we were confidently able to calculate AOM rates, mcrA gene abundances correlate positively with rates when plotted on a log-log scale (Fig. S3).

\section{Microbial community diversity and analysis.}

The three most abundant classes in our dataset, the Methanomicrobia, Deltaproteobacteria, and JS1, a class of Atribacteria, are especially dominant in communities from cores experiencing recent methane influx (Fig. 3C). Besides these major groups, other poorly-understood taxa include the Aminicenantes, Anaerolineae, and Phycisphaerae, all thought to be fermentative saccharolytic heterotrophs ${ }^{41,42,43}$. Dehalococcoidia, also present, contain members capable of reductive dehalogenation ${ }^{44}$. Among all ASVs in our dataset, we identified ninety-nine whose relative abundances were significantly different across communities when grouped according to methane dynamics (Fig. 5). These ASVs on average comprise $12.7 \%$ of the sequences in communities associated with active seepage, $1.6 \%$ of communities experiencing methane flux, and $9.7 \%$ of steady-state communities. When compared to the other two regimes, communities from sites displaying steady-state sulfate-methane dynamics contained higher abundances of several ASVs belonging to Aminicenantia, Dehalococcoidia, and Woesearchaeota (Fig. 5). In addition, one ANME-1a ASV was higher in this group, though only three of the 41 ANME ASVs in the entire dataset were differentially abundant across methane regimes. Several ASVs belonging to SEEPSRB1 and Desulfatiglans also displayed variation among regimes (Fig. 5).

In communities from cores experiencing high methane flux, Shannon-Weiner alpha diversity indices decrease as depths approach peak model-derived AOM rates (Fig. 6A). Linear regressions show no such decrease in diversity across AOM peaks from steady-state areas (Fig. 6B). Interestingly, in samples from 
core GC1069, highest diversity is seen at depths of peak AOM, while the opposite is apparent in GC1070 (Fig. 6B).

Differences in community structure are evident across regimes of methane dynamics, with communities from PC1029 showing especially clear separation from those in steady-state cores (Fig. 7A). These distinctions were still observed even when seep samples were omitted $\left(R^{2}=0.06, p<0.001\right)$, and when samples from above or below the SMT were considered separately $\left(\mathrm{R}^{2}=0.19, p=0.003 ; \mathrm{R}^{2}=0.22, p=\right.$ 0.001 respectively). In addition, we classify samples according to three geochemical zones they inhabit based on the shapes of porewater sulfate profiles: the linear sulfate reduction (SR) zone, the nonlinear SR zone impacted by recent methane influx, and below-SMT. Community structure also varied significantly across these redox zones, though PERMANOVA tests revealed only $9.6 \%$ of the variance among communities could be explained by redox zone (Fig. 7B) as compared to $19.7 \%$ by methane regime. Though containing high relative abundances of ANME, communities in nonlinear SR regions of cores experiencing increasing methane flux were more similar to below-SMT communities than those in linear SR zones, suggestive of recent adaptations to methane influx (Fig. S4). Aside from methane regimes and redox zones, communities also varied significantly by the GHM and core they were sampled from (32.5\% and $22.7 \%$ of variance), suggesting these Arctic GHM communities contain a high degree of biogeographic heterogeneity ${ }^{27}$ that remains unconstrained.

\section{Discussion}

The presence of distinct regimes of methane flux at Storfjordrenna GHMs allows us to examine concomitant changes in inferred AOM activity and microbial community composition. We conceptually summarize results from integrated geochemical, numerical, and microbiological analyses that characterize three distinct biogeochemical regimes corresponding to changes in methane supply across all seven cores (Fig. 8).

In panel A, steady-state sulfate-methane dynamics occur when methane consumption is balanced by sulfate diffusion from seawater. ANME and SRB abundances often do not peak around the SMT, and these populations are accompanied by several other microbial groups, many of which may be slowgrowing anaerobic fermenters of organic matter. Growth of biofilms at SMTs may also be supported over long timescales, if given steady supplies of methane and sulfate. In panel B, AOM draws down sulfate and a SMT is established, though it has not reached steady-state dynamics. At GC1045, diffusion modeling of sulfate porewater profiles indicate the methane front began around 290 years ago. As methane flux increases, this pulse diffuses upwards, stimulating AOM in increasingly shallow sediment layers. AOM rates are approximately an order of magnitude higher than in panel $A$, supporting the growth of ANME/SRB and decreasing microbial community diversity. In panel C, gas seepage and the presence of hydrates at PC1029 indicate methane is at or above saturation in porewaters throughout the core. Sulfate is delivered into the sediment column through seawater infiltration driven by bubble-driven convection, bioirrigation by frenulate siboglinids, or reoxidation of sulfide by their endosymbionts. High sulfate concentrations predict high (though unconstrained) AOM rates, supporting large populations of 
ANME and SRB based on respective counts of $m c r A$ and $d s r A B$. Though direct cell counts were not obtained, the presence of several other abundant bacterial and archaeal classes suggests these shallow sediments support high cell densities overall.

Model-derived methane fluxes from Storfjordrenna cores GC1045 and 1081 are an order of magnitude higher than those from seeps associated with pockmark features at Vestnessa Ridge, west of Svalbard ${ }^{45}$. When compared to other estimates across continental margins worldwide, the values we report for these two cores are high but well within reported ranges, while fluxes from steady-state cores fall within the middle ${ }^{46}$. At the seep site, PC1029, our methane flux estimate on the order of $10^{2} \mathrm{~mol} \mathrm{~m}^{-1} \mathrm{yr}^{-1}$ is several times the maximum of other modeled AOM rates at seep sites ${ }^{46}$, but less than the highest empirically measured AOM rate ${ }^{6}$. We acknowledge that the rate estimated from PC1029 is associated with large uncertainties, as we were not able to satisfactorily fit the modeled curve to empirically-derived sulfate data under the current setup of the model. The model currently does not consider gaseous phase transport or bioturbation, which would enhance gaseous methane transport from deeper sediments, nor does it include sulfate infiltration from the bottom water or sulfide oxidation, which may provide additional substrates for SR-AOM. Though the timing of seepage at the center of GHM3 is unconstrained, the large populations of anaerobic methanotrophs and sulfate reducers supported by high methane fluxes may indicate stable conditions over timescales of years ${ }^{47}$.

We now consider ANME doubling times at sites experiencing an increase in methane flux. If we interpret the downcore increases in mcrA concentrations approaching the SMT (Fig. 3D) as methane-fueled ANME growth, doubling times of 147 days (GC1081, 23 to $56.5 \mathrm{~cm}$ ) to 261 days (GC1045, 66 to $76 \mathrm{~cm}$ ) can be derived by assuming one copy of $m c r A$ per ANME genome ${ }^{48}$. These values complement the only other published estimate of in situ ANME doubling time, at approximately 100-200 days ${ }^{47}$. We can then estimate per-cell AOM rates across SMTs at an average of $0.65 \mathrm{pmol} \mathrm{CH}_{4} \mathrm{~d}^{-1}$, comparable to the $0.5-1.8$ reported in a bioreactor where $\mathrm{AOM}$ was stimulated ${ }^{49}$. The observation that AOM rates and $\mathrm{mcr} A$ abundances in areas experiencing increasing methane flux peak at nearly the same depths suggests that the notoriously slow ANME doubling times may not present a significant lag (only 0-1 years) in the response of the benthic biogeochemical methane filter, in contrast with findings from a prior modeling study from coastal ocean sediments with methane produced in-situ through acetotrophic methanogenesis ${ }^{50}$.

At Storfjordrenna GHMs, ANME-1 is the most abundant anaerobic methanotroph in nearly all communities (Figs. 2C, 3C, 4B). However, our observations of ANME-2 at sulfate-rich surface sediments in PC1029 (Fig. 4B) agree with previous findings ${ }^{5}$. At all other depths and locations, the reasons for ANME-1 dominance at Storfjordrenna GHMs is unclear. Genomic explanations may include the lack of an energetically expensive nifDHK nitrogenase in ANME-1 ${ }^{51}$, and fewer multi-heme cytochromes thought to be involved in direct intercellular electron transfer ${ }^{52}$. Additionally, the lack of mer in ANME- $1^{53}$, and the suggestion of $m e t^{54}$ or fae, hps, and $a d h^{55}$ as functional replacements in the reverse methanogenesis pathway suggest that separate niches could exist for these two clades, but this remains an open 
question. In cores experiencing increased methane flux, ANME-1a and ANME- $1 \mathrm{~b}$ were present at nearequal abundances, with ANME-1b sequences more abundant at shallower depths. In contrast, the $1 \mathrm{a}$ subclade was more dominant in three of four steady-state cores (Figs. 2C, 3C). ANME percent abundances and $m c r A$ concentrations are mostly higher in cores experiencing increasing methane flux (Figs. 2, 3, 4). This may point towards a boom-and-bust cycle where methane influx into shallower sediment layers quickly stimulates a large but ultimately unsustainable methanotrophic population, which may decline as sulfate is drawn down or as other community members establish.

In several instances, high abundances of ANME or concentrations of $m c r A$ are seen at depths above those where methane is expected (in GC1081 and GC1048) or below the SMT (GC1069). These may reflect the limited resolution of our alkalinity and sulfate measurements. At GC1068 and GC1069, any cessation in the methane supply would allow sulfate to diffuse into a deeper depth without affecting the linearity of the sulfate profile. Alternatively, this may indicate inactive relic communities, though ANME-1 may still be capable of $\mathrm{AOM}^{56}$ or even methanogenesis ${ }^{57}$ when starved of sulfate.

Co-occurrences between ANME-1b and SEEP-SRB2 have been reported ${ }^{2}$, and their relative abundances appear to mirror each other in GHM4 samples (Fig. 3C). Both clades of SEEP-SRB, as well as Desulfatiglans -the most common SRB genus unaffiliated with ANME in our dataset-are presumed to oxidize a wide variety of reduced hydrocarbons ${ }^{35}$. The presence of several potentially fermentative and saccharolytic clades like the Atribacteria, Aminicenantes, Anaerolineae, and Phycisphaerae may reflect alternate organic matter-dependent metabolic strategies that are interrupted by ANME and SRB when methane enters sulfate-rich porewaters. Macroscopic ANME-dominated biofilms found at two SMTs in GC1048 and GC1070 36 contained mcrA in concentrations of up to $7.6 \times 10^{10} \mathrm{~g}^{-1}$. We hypothesize these biofilms reflect sediment regimes that have experienced steady methane and sulfate supply over many years. ANME biofilms have been described at SMTs in other subseafloor locations, often in fracturedominated $\operatorname{cores}^{58}$.

Microbial communities inhabiting Storfjordrenna GHMs show lower richness and evenness than most other reported communities from methane seeps, sulfate-methane transition zones, and marine subsurface environments ${ }^{2}$. Broadly, diversity decreases with depth, but only significantly across depths corresponding to peak AOM rates in high methane flux areas (Fig. 6). This decrease is still evident when other metrics of richness (number of ASVs) and evenness (inverse Simpson) are used (data not shown). In communities recently impacted by methane flux (i.e. inhabiting non-steady-state SR zones of cores where methane flux is increasing), this decrease in diversity and convergence towards a community type found below SMTs may be associated with certain taxa being outcompeted by ANME/SRB on timescales of years as the methane front progresses. Cell generation times can decrease by several orders of magnitude across the SMT, below which community assembly can be influenced more by the slow growth of few taxa, such as Atribacteria, capable of thriving in an energy-limited environment than by evolutionary adaptation during burial ${ }^{59}$. 
Below-SMT communities are dominated by Atribacteria of the JS1 class (Figs. 3C, 4B), while similar observations have been reported in methane-rich deep Antarctic marine sediments ${ }^{60}$ and in a submarine mud volcano offshore Japan ${ }^{61}$. Four JS1 ASVs were identified across different regimes of methane flux and positions above or below the SMT (Fig. 5), though interestingly, one of them (ASV91) was preferentially abundant in above-SMT steady-state and below-SMT increasing-flux communities, evidence towards its persistence during methane migration into shallower sediment horizons. Despite steady-state communities showing larger numbers of differentially abundant ASVs, two Calditrichia (genus Caldithrix) were higher in communities experiencing increased methane flux, while four Campylobacteria from the genera Sulfurimonas and Sulfurovum and seven Gammaproteobacteria were associated with active methane seepage (Fig. 5). Sulfurovum is capable of oxidizing elemental sulfur or thiosulfate using oxygen or nitrate as electron acceptors ${ }^{32}$.

The presence of differentially abundant ASVs at distinct regimes may reflect the sampling of comparatively shallow sediments at PC1029, and an influence from macrofauna. Sulfur-oxidizing gammaproteobacterial symbionts of the siboglinid frenulate Oligobrachia have previously been reported in cold seeps ${ }^{62}$. Notably, there is an absence of Oligobrachia and a decreased prevalence of seafloor bacterial mats at GHM5, where steady-state cores were collected ${ }^{21}$. Despite the short (several km) distances between individual GHMs, many interdependent factors, such as physical disturbances, differences in fluid flow regimes, and colonization of foundation species provide heterogeneity across seep ecosystems ${ }^{63}$.

\section{Summary and prospective}

In summary, our integrated approach allows us to detail regimes of methane transport where 1) steadystate sulfate-methane dynamics supports moderate rates of AOM at SMTs, low ANME/SRB populations, and a diverse community of organic matter degraders; 2 ) as methane flux increases, diffusion of methane into shallower sediment horizons stimulates ANME growth therein with little lag time; 3 ) seepage and sulfate transport into shallow sediments support high populations of ANME and SRB. Cold seeps are dynamic systems that undergo temporal perturbations in methane flux. These results highlight the importance of framing microbial community data and estimates of their metabolic processes within a spatially and temporally constrained geochemical context to more thoroughly understand microbial contributions in structuring habitats and mediating biogeochemical cycles.

The incorporation of genomic data into reactive transport models describing other microbially-mediated processes has demonstrated utility in predicting subsurface microbial responses ${ }^{64}$. A modeling scenario that considers the dynamics of ANME growth may be of use in constraining estimates of marine subsurface methane flux into the hydrosphere. Global microbial methane filter efficiencies of $50-60 \% 5$ have been used in modeling studies ${ }^{19}$, but seep sites display wide heterogeneity ${ }^{6}$. Our finding that $m c r A$ gene copy numbers correlate positively with modeled AOM rates provides some justification for coupling these populations and their associated activities (Fig. S3), mirroring the coupling of methane fluxes and 
transcripts of methane cyclers in peat soils ${ }^{65}$. Though microbial community data can provide explanatory power for predicting ecosystem processes, community changes do not always coincide with processes being measured ${ }^{66}$. At higher resolutions, -omics strategies capable of characterizing functional genes, transcripts, pathways, and draft genomes can link sequence data with processes and characterize ecosystem changes ${ }^{67}$, or even apply these data into biogeochemical models to infer the presence of cryptic cycles ${ }^{68}$. Further studies could apply the framework discussed here towards interpreting the biogeochemistry of seep ecosystems at other locations, or to other microbially-mediated cycles constrained by distinct mechanisms of solute transport.

\section{Methods}

\section{Fieldwork and Sample Collection}

Samples and data were collected aboard the RV Helmer Hanssen on CAGE cruise 16-5, from June $16^{\text {th }}$ to July $4^{\text {th }}, 2016$. Bathymetric data were acquired with the RV Helmer Hanssen's shipboard Kongsberg Simrad EM 302 multibeam echo sounder using a max. frequency of $34 \mathrm{KHz}$ and a max. swath as a function of depth of 5.5. Gas flares were detected with single (split)-beam EK60 and multibeam EM302 echosounders using 18 and $38 \mathrm{KHz}$ transducers.

Gravity core (GC) 1045 was recovered from the south slope of GHM3, and GCs 1068-1070 from three locations at GHM5. GC1081 was collected from gas seepage area at GHM4. Once recovered, the plastic liner containing the core was removed from the barrel, sectioned into $1 \mathrm{~m}$ segments, labeled, and split in half with a table saw to obtain working and archive halves. Core halves were stored horizontally at $4^{\circ} \mathrm{C}$. Following sectioning, Rhizons were used to sample porewater on archive halves. Sediment headspace gas samples for methane measurements were collected from depressurized cores, and thus should be considered underestimates for in situ concentrations. $5 \mathrm{ml}$ bulk sediment was collected with cutoff plastic syringes from the working half of the core, transferred to $20 \mathrm{ml}$ headspace glass vials with $5 \mathrm{ml}$ $1 \mathrm{M} \mathrm{NaOH}$ and 2 glass beads, capped with rubber septa and aluminum crimpers, and stored at $2^{\circ} \mathrm{C}$. Total alkalinity (TA) was titrated onboard less than a few hours after the syringes were detached from the Rhizons. Depending on the expected TA, we used 0.1 to $0.5 \mathrm{ml}$ of porewater for titration in an open beaker with constant stirring. $\mathrm{pH}$ was manually recorded with every addition of $0.0012 \mathrm{M} \mathrm{HCl}$. 7-10 measurements were performed for every sample. TA was calculated from the recorded $\mathrm{pH}$ and amount of acid added using the Gran function. Details of the calculation were reported previously ${ }^{69}$. Increases in porewater alkalinity determined by onboard titrations were used to roughly constrain the SMT depths (within $30 \mathrm{~cm}$ ) for sampling purposes.

Sediment microbiology samples of $2 \mathrm{~cm}$ depth were then taken every 5-10 cm near the SMT and every 20-50 cm above and below it. Less than 12 hours after cores were collected, ethanol-sanitized spatulas were used to scrape away the outer several $\mathrm{mm}$ of sediment from the working core half, and $\sim 100 \mathrm{~g}$ from the interior of each sample was placed into a sterile whirlpak bag (VWR) and immediately frozen at $-80^{\circ} \mathrm{C}$. 
Replicate PVC push cores for geochemical and microbiological sampling were collected $\sim 30 \mathrm{~cm}$ from the seep at GHM3 using a Sperre Subfighter 30k remotely operated vehicle (ROV) equipped with a raptor arm from the Centre for Autonomous Marine Operations and Systems (AMOS). Recovery ranged from 23 to $50 \mathrm{~cm}$. Rhizons were used to extract porewater from one core, and microbiology samples were extruded on deck from the other in 2-cm sections using an ethanol-sanitized spatula. These were placed into sterile bags and frozen immediately at $-80^{\circ} \mathrm{C}$. Deep-frozen sediment samples were shipped from UiT-Troms $\emptyset$ to Oregon State University (OSU) in a Cryo Solutions MVE Doble 47 dry shipper and were subsequently stored at $-80^{\circ} \mathrm{C}$.

\section{Geochemistry}

Sulfate content in porewater was analyzed by a Dionex ICS1100 ion chromatography (IC) at the Geological Survey of Norway (NGU). An lonPac AS23 column was equipped on the IC with the eluent (4.5 $\mathrm{mM} \mathrm{NaCO}_{3}$ and $0.8 \mathrm{mM} \mathrm{NaHCO}_{3}$ ) flow set to be $1 \mathrm{~mL} / \mathrm{min}$. Due to a dilution issue when analyzing sulfate concentrations with IC, measured values were corrected by assuming a constant chloride concentration of $556 \mathrm{mM}$ across the samples. From our previous knowledge of chloride concentration in the region, the concentration can be at most $4 \%$ apart from the concentration we assigned for correction (this translates to a few $\mathrm{mM}$ uncertainty in the sulfate concentration, though error bars are barely visible beyond widths of points). However, this correction does not affect our interpretation of methane dynamics based on sulfate profiles, as we observed concomitant increases in alkalinity from TA measurements.

Total sulfide ( $\Sigma \mathrm{HS})$ concentrations were measured spectrophotometrically following the Cline method ${ }^{70}$. Samples were preserved onboard with $23.8 \mathrm{mM} \mathrm{Zn}(\mathrm{OAc})_{2}$ solution onboard $<30$ minutes after the syringes were disconnected from the Rhizons. The samples were then kept frozen until shore-based analysis. Details of the analyses were also given in Latour et $\mathrm{al}^{69}$. Depending on the factor of dilution, the detection limit is around tens of $\mu \mathrm{M}$. To determine the concentration of dissolved methane in the porewater of the sediment matrix, a conventional headspace method was applied ${ }^{17}$.

Gas measurements were performed using a Thermo Scientific Trace 1310 gas chromatograph equipped with a flame ionization detector (GC-FID) and a Thermo Scientific TG-BOND alumina $\left(\mathrm{Na}_{2} \mathrm{SO}_{4}\right)$ column $(30 \mathrm{~m} \times 0.53 \mathrm{~mm} \times 10 \mu \mathrm{m})$.

\section{Modeling}

For the sites with non-steady-state porewater profiles (GC1045 and GC1081), we applied the same reduced modeling scheme as described previously ${ }^{14}$. Only sulfate and methane were considered in this reduced model, with $\mathrm{AOM}$ as the only reaction consuming both constituents. We assigned the diffusion coefficients of sulfate and methane to be $1.58 \times 10^{-2}$ and $3.01 \times 10^{-2} \mathrm{~m}^{2} \mathrm{yr}^{-1}$, respectively, when corrected for tortuosity and temperature. We simulated a 60-meter sediment column, which is the bottom of the gas hydrate stability zone in the area. AOM rates were controlled by the theoretical maximum rate, methane 
and sulfate concentrations, and the lower boundary condition of methane. The theoretical maximum AOM rate was determined to be $2 \mathrm{~mol} \mathrm{~m}^{-3} \mathrm{yr}^{-1}$, based on fitting porewater profiles around the depth of the SMT for all cores ${ }^{14}$. Different lower boundary conditions of methane were assigned, which were constrained by the curvatures of the sulfate profiles. A higher concentration of methane for the lower boundary condition results in a more abrupt change in the sulfate concentration gradient, and vice versa. We assigned seawater sulfate and methane concentrations for the initial and upper boundary conditions; a no-flux lower boundary condition was used for sulfate.

For the sites with steady-state porewater profiles, we applied the comprehensive modeling scheme as described previously ${ }^{14}$. We coupled the CrunchFlow routine for this simulation with profiles of sulfate, $\Sigma H S, T A$, calcium, magnesium, and ammonium to constrain the reaction network. Because ammonium concentration measurements were not available for these sites, we assumed a similar profile, and therefore the same organic matter degradation rate, as in core GC920 from a previous study ${ }^{14}$. Seawater composition was used for upper and initial conditions for all solutes. Except for methane, no-flux lower boundary conditions were assigned for all solutes. Methane was produced at the deepest cell in the model from an imaginary mineral. Such a setup is to simulate a methane source that was not produced in situ in the sediments, and to overcome the limitation of the software package used that required all solutes to have the same boundary condition. A detailed description of the reaction network can be found

in Hong et al. (2017) ${ }^{14}$. Depth-integrated fluxes were calculated by summing the product of modeled AOM rates and the cell thickness, considering all modeled AOM rates from above the methanogenic zone. GC1048 is a special case compared with the other steady-state sites: Its sulfate profile is also slightly bent as in the profiles of GC1045 and GC1081. To satisfactorily fit this observation, we similarly applied a slightly intensifying methane flux when we modeled GC1048. However, the increase in methane flux we assigned for GC1048 is much smaller than in the two sites with obvious non-steady-state sulfate profiles. To eliminate concerns that only three porewater samples were collected above the SMTs which may lead to misinterpretation of the status of pore fluid system (i.e., steady-state vs. increasing methane flux), we also fit the porewater profiles from the four steady-state sites with model results for scenarios that assume an increase in methane flux (Fig. S5). Despite the scarcity of this sulfate data collected, we conclude it is difficult to misinterpret these as steady-state sites. For both modeling approaches, more detail including assumptions, equations, and setup is provided in supplementary information.

\section{DNA Extraction, Amplification, Sequencing, and Analysis}

DNA was extracted from sediments in a clean laminar flow hood using a Qiagen DNeasy PowerSoil kit following the manufacturer's protocol. The Earth Microbiome Project 16S Illumina Protocol was used to prepare amplicons for sequencing. Briefly, V4 regions of bacterial and archaeal 16s rRNA genes were amplified in triplicate $25 \mathrm{ul}$ reactions using universal 515 -forward and 806 -reverse primers ${ }^{71}$ modified with dual-indexed Illumina sequencing adapters ${ }^{72}$. The thermal cycling protocol of Caporaso et al $2011^{71}$ was followed without modifications. After confirming amplification with agarose gel electrophoresis, triplicate PCR products were pooled and purified with a Qiagen QIAquick PCR purification kit. Amplicon 
concentrations were quantified with a Qubit fluorometer using the Qubit dsDNA high sensitivity assay kit and pooled in equimolar amounts. Illumina Miseq V2 paired-end 250 bp sequencing was performed by technicians at Oregon State University's Center for Genome Research and Biocomputing (CGRB). Two sediment-free DNA extraction blanks were amplified and included in the sequencing run.

Working in $\mathrm{R}$ version 3.6.1, $16 \mathrm{~S}$ rRNA amplicon data was processed with DADA2 ${ }^{73}$ (version 1.12.1) following an established pipeline ${ }^{74}$. Reads were denoised, chimeras removed, and taxonomies classified using version 132 of the SILVA nonredundant $16 \mathrm{~S}$ reference database ${ }^{75}$. Sequences were aligned with DECIPHER $^{76}$ (version 2.12), and a phylogenetic tree was constructed using phangorn ${ }^{77}$ (version 2.5.5). Phyloseq $^{78}$ (version 1.28.0) was used to combine read count data with sample and taxonomy information. Sequences identified as Eukaryotes, Chloroplasts, or Mitochondria were removed, and the "combined" method of decontam ${ }^{79}$ (version 1.4.0) was then used to identify and remove 81 contaminant ASVs. In addition, after noticing the presence of Micrococcus in one blank sample, all four ASVs from this genus were manually removed. In total, the removed ASVs comprised $1.05 \%$ of the reads in the dataset.

Blanks and other samples with less than 8,931 reads were removed, and alpha diversity metrics (ASV richness, Chao1, Shannon, and Simpson indices) were then determined. Using vegan ${ }^{80}$ (version 2.5-6), weighted Unifrac ${ }^{81}$ distances calculated from a Hellinger-transformed ASV count table, and PERMANOVA tests were run to assess differences in community structure among groups. DESeq2 ${ }^{82}$ (version 1.24.0) was used to identify differentially abundant ASVs among three discrete regimes of methane dynamics. Each above-SMT methane regime was compared against the other two combined. Below-SMT samples only included two regimes, because all active seepage samples from PC1029 had sulfate concentrations above $1 \mathrm{mM}$. In this core, where AOM rates could only be roughly estimated, we used a peak AOM rate depth of $13 \mathrm{~cm}$, which corresponded to the steepest decline in porewater sulfate.

\section{Droplet Digital PCR}

Droplet digital PCR (ddPCR) was used to quantify abundances of functional genes dsrAB and mcrA using primer pairs described by Kondo ${ }^{83}$ and Luton ${ }^{84}$, respectively. Reactions of 22 ul volume were prepared in a clean PCR hood in 96-well plates using 1x Bio-Rad QX200 ddPCR EvaGreen Supermix, 200 nM primers, and and 0.88 ul of tenfold-diluted genomic DNA. Droplets were generated on a QX200 AutoDG Droplet Generator using automated droplet generation oil for EvaGreen Supermix (Bio-Rad). Thermal cycling was performed immediately afterwards on a Veriti 96-well thermal cycler. Protocols began with a single initialization step at $95^{\circ} \mathrm{C}$ for 5 minutes and then proceeded to 40 cycles of denaturation at $95^{\circ} \mathrm{C}$ for 30 seconds, annealing for 1 minute (at a temperature of 53 for $m c r A$ and 58 for $d s r A B$ ), and for $m c r A$ only, an extension at $72^{\circ} \mathrm{C}$ for 75 seconds. Signal stabilization steps $\left(4^{\circ} \mathrm{C}\right.$ for 5 minutes, then $90^{\circ} \mathrm{C}$ for 5 minutes) were then performed before maintaining a $4^{\circ} \mathrm{C}$ hold. To ensure uniform heating of all droplets, the ramp rate for all amplification cycles was set to $2^{\circ} \mathrm{C} /$ minute. Reactions were kept at $4^{\circ} \mathrm{C}$ overnight and read with the Bio-Rad QX200 Droplet Reader the following morning. Droplet generation and reading were performed by the lead author at OSU's CGRB core facility. Normalization was performed by inspecting 
fluorescence distributions using Quantasoft software (Bio-Rad). Threshold fluorescence values were manually imposed by visually inspecting distributions of DNA extraction blank and no-template-added control samples. Amplicon copy numbers per well were then converted to copies per gram wet sediment.

\section{Declarations}

\section{Data Availability}

Raw sequence data and associated metadata have been deposited to the NCBI Sequence Read Archive (BioProject \#PRJNA533183). Other data used in this study (geochemical data, modeled rates, and phyloseq objects) have been made publicly available at https://github.com/sklasek/svalflux.

\section{Acknowledgements}

We thank the officers and crew of R/V Helmer Hanssen on the CAGE cruise 16-5, cruise leader Michael Carroll, chief engineers Bjørn Runar Olsen, Pedro De La Torre, Frode Volden, and researcher Stein Nornæs from the Centre for Autonomous Marine Operations and Systems (AMOS) for helping with sample acquisition and ROV operation. We also thank Stefan Bünz for providing bathymetric data acquired by the Norwegian Centre of Excellence, Centre for Arctic gas hydrates, Environment, and Climate (CAGE). Mark Dasenko, Anne-Marie Girard Pohjanpelto, and Jessica Nixon at the Oregon State University Center for Genome Resources and Biocomputing (CGRB) provided support with DNA sequencing and droplet digital PCR. Arunima Sen gave helpful interpretations of tubeworm observations and behavior. This work is supported by the Research Council of Norway (RCN) through its Centres of Excellence funding scheme project no. 223259, and also by the U.S. Department of Energy (DE-FE0013531). S.R. was supported by the US National Science Foundation Research Experience for Undergraduate (REU) program. M.E.T. acknowledges a fellowship from the Hanse-Wissenschaftskolleg (HWK), Germany. W.H. acknowledges the support from the RCN-funded project NORCRUST (grant no. 255150).

\section{Author Contributions}

SAK and WH designed the study, participated in fieldwork, generated data, analyzed results, and wrote the manuscript. FG participated in fieldwork and contributed methane measurements. AP participated in fieldwork and provided bathymetric mapping. SR and $\mathrm{KH}$ assisted with lab work. MET and FSC analyzed and interpreted results and edited the manuscript.

\section{Additional Information}

Competing financial interests: The authors declare no competing financial interests.

\section{References}


1. Reeburgh, W. S. Oceanic Methane Biogeochemistry. Chem. Rev. 107, 486-513 (2007).

2. Ruff, S. E. et al. Global dispersion and local diversification of the methane seep microbiome. PNAS 112, 4015-4020 (2015).

3. Nauhaus, K., Boetius, A., Krüger, M. \& Widdel, F. In vitro demonstration of anaerobic oxidation of methane coupled to sulphate reduction in sediment from a marine gas hydrate area. Environmental Microbiology 4, 296-305 (2002).

4. Nauhaus, K., Albrecht, M., Elvert, M., Boetius, A. \& Widdel, F. In vitro cell growth of marine archaealbacterial consortia during anaerobic oxidation of methane with sulfate. Environmental Microbiology 9, 187-196 (2007).

5. Knittel, K. \& Boetius, A. Anaerobic Oxidation of Methane: Progress with an Unknown Process. Annual Review of Microbiology 63, 311-334 (2009).

6. Boetius, A. \& Wenzhöfer, F. Seafloor oxygen consumption fuelled by methane from cold seeps. Nature Geoscience 6, 725-734 (2013).

7. Ruppel, C. Methane Hydrates and Contemporary Climate Change. 11 (2011).

8. Shakhova, N. et al. Extensive Methane Venting to the Atmosphere from Sediments of the East Siberian Arctic Shelf. Science 327, 1246-1250 (2010).

9. Portnov, A. et al. Offshore permafrost decay and massive seabed methane escape in water depths >20 m at the South Kara Sea shelf. Geophysical Research Letters 40, 3962-3967 (2013).

10. Saint-Ange, F. et al. Multiple failure styles related to shallow gas and fluid venting, upper slope Canadian Beaufort Sea, northern Canada. Marine Geology 355, 136-149 (2014).

11. Westbrook, G. K. et al. Escape of methane gas from the seabed along the West Spitsbergen continental margin: ARCTIC METHANE GAS PLUMES. Geophysical Research Letters 36 (2009).

12. Mau, S. et al. Widespread methane seepage along the continental margin off Svalbard - from Bjørnøya to Kongsfjorden. Sci Rep 7, (2017).

13. Berndt, C. et al. Temporal Constraints on Hydrate-Controlled Methane Seepage off Svalbard. Science 343, 284-287 (2014).

14. Hong, W.-L. et al. Seepage from an arctic shallow marine gas hydrate reservoir is insensitive to momentary ocean warming. Nature Communications 8, 15745 (2017).

15. Paull, C. K. et al. Origin of pingo-like features on the Beaufort Sea shelf and their possible relationship to decomposing methane gas hydrates. Geophys. Res. Lett. 34, L01603 (2007).

16. Serov, P., Portnov, A., Mienert, J., Semenov, P. \& llatovskaya, P. Methane release from pingo-like features across the South Kara Sea shelf, an area of thawing offshore permafrost. Journal of Geophysical Research: Earth Surface 120, 1515-1529 (2015).

17. Serov, P. et al. Postglacial response of Arctic Ocean gas hydrates to climatic amelioration. PNAS 114, 6215-6220 (2017).

18. Niemann, H. et al. Microbial methane turnover at mud volcanoes of the Gulf of Cadiz. Geochimica et Cosmochimica Acta 70, 5336-5355 (2006). 
19. Biastoch, A. et al. Rising Arctic Ocean temperatures cause gas hydrate destabilization and ocean acidification. Geophys. Res. Lett. 38, L08602 (2011).

20. Spielhagen, R. F. et al. Enhanced Modern Heat Transfer to the Arctic by Warm Atlantic Water. Science 331, 450-453 (2011).

21. Sen, A. et al. Geophysical and geochemical controls on the megafaunal community of a high Arctic cold seep. Biogeosciences Discussions 1-52 (2018) doi:10.5194/bg-2017-540.

22. Haug, T. et al. Future harvest of living resources in the Arctic Ocean north of the Nordic and Barents Seas: A review of possibilities and constraints. Fisheries Research 188, 38- 57 (2017).

23. Andreassen, K. et al. Massive blow-out craters formed by hydrate-controlled methane expulsion from the Arctic seafloor. Science 356, 948-953 (2017).

24. Kessler, J. D. et al. A Persistent Oxygen Anomaly Reveals the Fate of Spilled Methane in the Deep Gulf of Mexico. Science 1199697 (2011) doi:10.1126/science.1199697.

25. Ruff, S. E. et al. In situ development of a methanotrophic microbiome in deep-sea sediments. The ISME Journal 1 (2018) doi:10.1038/s41396-018-0263-1.

26. Klasek, S. A. et al. Deep-Sourced Fluids From a Convergent Margin Host Distinct Subseafloor Microbial Communities That Change Upon Mud Flow Expulsion. Front. Microbiol. 10, (2019).

27. Carrier, V. et al. The Impact of Methane on Microbial Communities at Marine Arctic Gas Hydrate Bearing Sediment. Front. Microbiol. 11, (2020).

28. Hensen, C. et al. Control of sulfate pore-water profiles by sedimentary events and the significance of anaerobic oxidation of methane for the burial of sulfur in marine sediments. Geochimica et Cosmochimica Acta 67, 2631-2647 (2003).

29. Haeckel, M., Suess, E., Wallmann, K. \& Rickert, D. Rising methane gas bubbles form massive hydrate layers at the seafloor. Geochimica et Cosmochimica Acta 68, 4335-4345 (2004).

30. Borowski, W. S., Paull, C. K. \& Ussler, W. Marine pore-water sulfate profiles indicate in situ methane flux from underlying gas hydrate. Geology 24, 655-658 (1996).

31. Hong, W.-L. et al. Variations in Gas and Water Pulses at an Arctic Seep: Fluid Sources and Methane Transport. Geophysical Research Letters 45, 4153-4162 (2018).

32. Inagaki, F. Sulfurovum lithotrophicum gen. nov., sp. nov., a novel sulfur-oxidizing chemolithoautotroph within the -Proteobacteria isolated from Okinawa Trough hydrothermal sediments. INTERNATIONAL JOURNAL OF SYSTEMATIC AND EVOLUTIONARY MICROBIOLOGY 54, 1477-1482 (2004).

33. Nobu, M. K. et al. Phylogeny and physiology of candidate phylum 'Atribacteria' (OP9/JS1) inferred from cultivation-independent genomics. The ISME Journal 10, 273-286 (2016).

34. Knittel, K. et al. Activity, Distribution, and Diversity of Sulfate Reducers and Other Bacteria in Sediments above Gas Hydrate (Cascadia Margin, Oregon). Geomicrobiology Journal 20, 269-294 (2003). 
35. Kleindienst, S., Ramette, A., Amann, R. \& Knittel, K. Distribution and in situ abundance of sulfatereducing bacteria in diverse marine hydrocarbon seep sediments. Environmental Microbiology 14, 2689-2710 (2012).

36. Gründger, F. et al. Methane-fuelled biofilms predominantly composed of methanotrophic ANME-1 in Arctic gas hydrate-related sediments. Scientific Reports 9, 9725 (2019).

37. Sen, A., Didriksen, A., Hourdez, S., Svenning, M. M. \& Rasmussen, T. L. Frenulate siboglinids at high Arctic methane seeps and insight into high latitude frenulate distribution. Ecology and Evolution 10, 1339-1351 (2020).

38. Sen, A. et al. Cryptic frenulates are the dominant chemosymbiotrophic fauna at Arctic and high latitude Atlantic cold seeps. PLoS One 13, (2018).

39. Cordes, E. E., Arthur, M. A., Shea, K., Arvidson, R. S. \& Fisher, C. R. Modeling the Mutualistic Interactions between Tubeworms and Microbial Consortia. PLOS Biology 3, e77 (2005).

40. Knittel, K., Lösekann, T., Boetius, A., Kort, R. \& Amann, R. Diversity and Distribution of Methanotrophic Archaea at Cold Seeps. Appl. Environ. Microbiol. 71, 467-479 (2005).

41. Sharon, l. et al. Accurate, multi-kb reads resolve complex populations and detect rare microorganisms. Genome Res. gr.183012.114 (2015) doi:10.1101/gr.183012.114.

42. Xia, Y., Wang, Y., Wang, Y., Chin, F. Y. L. \& Zhang, T. Cellular adhesiveness and cellulolytic capacity in Anaerolineae revealed by omics-based genome interpretation. Biotechnology for Biofuels 9,111 (2016).

43. Spring, S., Bunk, B., Spröer, C., Rohde, M. \& Klenk, H.-P. Genome biology of a novel lineage of planctomycetes widespread in anoxic aquatic environments. Environmental Microbiology 0, (2018).

44. Hiraishi, A. Biodiversity of Dehalorespiring Bacteria with Special Emphasis on Polychlorinated Biphenyl/Dioxin Dechlorinators. Microbes Environ. 23, 1-12 (2008).

45. Treude, T. et al. Biogeochemical Consequences of Nonvertical Methane Transport in Sediment Offshore Northwestern Svalbard. Journal of Geophysical Research: Biogeosciences 125, e2019JG005371 (2020).

46. Regnier, P. et al. Quantitative analysis of anaerobic oxidation of methane (AOM) in marine sediments: A modeling perspective. Earth-Science Reviews 106, 105-130 (2011).

47. Ruff, S. E. et al. In situ development of a methanotrophic microbiome in deep-sea sediments. The ISME Journal 13, 197-213 (2019).

48. Haroon, M. F. et al. Anaerobic oxidation of methane coupled to nitrate reduction in a novel archaeal lineage. Nature 500, 567-570 (2013).

49. Girguis, P. R., Cozen, A. E. \& DeLong, E. F. Growth and Population Dynamics of Anaerobic MethaneOxidizing Archaea and Sulfate-Reducing Bacteria in a Continuous-Flow Bioreactor. Appl. Environ. Microbiol. 71, 3725-3733 (2005).

50. Dale, A. W., Regnier, P. \& Cappellen, P. V. Bioenergetic Controls on Anaerobic Oxidation of Methane (AOM) in Coastal Marine Sediments: A Theoretical Analysis. Am J Sci 306, 246-294 (2006). 
51. Krukenberg, V. et al. Gene expression and ultrastructure of meso- and thermophilic methanotrophic consortia. Environmental Microbiology n/a-n/a doi:10.1111/1462-2920.14077.

52. McGlynn, S. E., Chadwick, G. L., Kempes, C. P. \& Orphan, V. J. Single cell activity reveals direct electron transfer in methanotrophic consortia. Nature 526, 531-535 (2015).

53. Meyerdierks, A. et al. Metagenome and mRNA expression analyses of anaerobic methanotrophic archaea of the ANME-1 group. Environmental Microbiology 12, 422-439 (2010).

54. Stokke, R., Roalkvam, I., Lanzen, A., Haflidason, H. \& Steen, I. H. Integrated metagenomic and metaproteomic analyses of an ANME-1-dominated community in marine cold seep sediments. Environmental Microbiology 14, 1333-1346 (2012).

55. Welander, P. V. \& Metcalf, W. W. Mutagenesis of the C1 Oxidation Pathway in Methanosarcina barkeri: New Insights into the Mtr/Mer Bypass Pathway. Journal of Bacteriology 190, 1928-1936 (2008).

56. Knab, N. J. et al. Regulation of anaerobic methane oxidation in sediments of the Black Sea. Biogeosciences Discussions 5, 2305-2341 (2008).

57. Lloyd, K. G., Alperin, M. J. \& Teske, A. Environmental evidence for net methane production and oxidation in putative ANaerobic MEthanotrophic (ANME) archaea: Methanogenesis and methanotrophy in ANME-1 archaea. Environmental Microbiology 13, 2548-2564 (2011).

58. Briggs, B. R. et al. Macroscopic Biofilms in Fracture-Dominated Sediment That Anaerobically Oxidize Methane. Applied and Environmental Microbiology 77, 6780-6787 (2011).

59. Starnawski, P. et al. Microbial community assembly and evolution in subseafloor sediment. PNAS 201614190 (2017) doi:10.1073/pnas.1614190114.

60. Carr, S. A., Orcutt, B. N., Mandernack, K. W. \& Spear, J. R. Abundant Atribacteria in deep marine sediment from the Adélie Basin, Antarctica. Front Microbio/ 6, 872 (2015).

61. Hoshino, T. et al. Atribacteria from the Subseafloor Sedimentary Biosphere Disperse to the Hydrosphere through Submarine Mud Volcanoes. Front. Microbiol. 8, (2017).

62. Lösekann, T. et al. Endosymbioses between bacteria and deep-sea siboglinid tubeworms from an Arctic Cold Seep (Haakon Mosby Mud Volcano, Barents Sea). Environmental Microbiology 10, 32373254 (2008).

63. Cordes, E. E. et al. The influence of geological, geochemical, and biogenic habitat heterogeneity on seep biodiversity. Marine Ecology 31, 51-65 (2010).

64. Scheibe, T. D. et al. Coupling a genome-scale metabolic model with a reactive transport model to describe in situ uranium bioremediation. Microbial Biotechnology 2, 274-286 (2009).

65. Freitag, T. E., Toet, S., Ineson, P. \& Prosser, J. I. Links between methane flux and transcriptional activities of methanogens and methane oxidizers in a blanket peat bog: Methane flux and transcriptional activities in a peat bog. FEMS Microbiology Ecology no-no (2010) doi:10.1111/j.15746941.2010.00871.x.

66. Bier, R. L. et al. Linking microbial community structure and microbial processes: an empirical and conceptual overview. FEMS Microbiol Ecol 91, (2015). 
67. Grossart, H.-P., Massana, R., McMahon, K. D. \& Walsh, D. A. Linking metagenomics to aquatic microbial ecology and biogeochemical cycles. Limnology and Oceanography 65, S2-S20 (2020).

68. Reed, D. C., Algar, C. K., Huber, J. A. \& Dick, G. J. Gene-centric approach to integrating environmental genomics and biogeochemical models. Proceedings of the National Academy of Sciences 111, 1879-1884 (2014).

69. Latour, P. et al. Dynamic interactions between iron and sulfur cycles from Arctic methane seeps. Biogeosciences Discussions 1-48 (2018) doi:10.5194/bg-2018-223.

70. Cline, J. D. Spectrophotometric Determination of Hydrogen Sulfide in Natural Waters1. Limnology and Oceanography 14, 454-458 (1969).

71. Caporaso, J. G. et al. Global patterns of $16 \mathrm{~S}$ rRNA diversity at a depth of millions of sequences per sample. Proceedings of the National Academy of Sciences 108, 4516-4522 (2011).

72. Kozich, J. J., Westcott, S. L., Baxter, N. T., Highlander, S. K. \& Schloss, P. D. Development of a DualIndex Sequencing Strategy and Curation Pipeline for Analyzing Amplicon Sequence Data on the MiSeq Illumina Sequencing Platform. Appl Environ Microbiol 79, 5112-5120 (2013).

73. Callahan, B. J. et al. DADA2: High resolution sample inference from Illumina amplicon data. Nat Methods 13, 581-583 (2016).

74. Callahan, B. J., Sankaran, K., Fukuyama, J. A., McMurdie, P. J. \& Holmes, S. P. Bioconductor Workflow for Microbiome Data Analysis: from raw reads to community analyses. F1000Res 5, 1492 (2016).

75. Quast, C. et al. The SILVA ribosomal RNA gene database project: improved data processing and webbased tools. Nucleic Acids Res 41, D590-D596 (2013).

76. Wright, E. S., Yilmaz, L. S. \& Noguera, D. R. DECIPHER, a Search-Based Approach to Chimera Identification for 16S rRNA Sequences. Appl Environ Microbiol 78, 717-725 (2012).

77. Schliep, K. P. phangorn: phylogenetic analysis in R. Bioinformatics 27, 592-593 (2011).

78. McMurdie, P. J. \& Holmes, S. phyloseq: An R Package for Reproducible Interactive Analysis and Graphics of Microbiome Census Data. PLOS ONE 8, e61217 (2013).

79. Davis, N. M., Proctor, D. M., Holmes, S. P., Relman, D. A. \& Callahan, B. J. Simple statistical identification and removal of contaminant sequences in marker-gene and metagenomics data. Microbiome 6, 226 (2018).

80. Oksanen, J. et al. vegan: Community Ecology Package. (2015).

81. Lozupone, C. A., Hamady, M., Kelley, S. T. \& Knight, R. Quantitative and Qualitative $\beta$ Diversity Measures Lead to Different Insights into Factors That Structure Microbial Communities. Appl. Environ. Microbiol. 73, 1576-1585 (2007).

82. Love, M. I., Huber, W. \& Anders, S. Moderated estimation of fold change and dispersion for RNA-seq data with DESeq2. Genome Biology 15, 550 (2014).

83. Kondo, R., Nedwell, D. B., Purdy, K. J. \& Silva, S. Q. Detection and Enumeration of Sulphate-Reducing Bacteria in Estuarine Sediments by Competitive PCR. Geomicrobiology Journal 21, 145-157 (2004). 
84. Luton, P. E., Wayne, J. M., Sharp, R. J. \& Riley, P. W. The mcrA gene as an alternative to 16 S rRNA in the phylogenetic analysis of methanogen populations in landfillb. Microbiology 148, 3521-3530 (2002).

\section{Figures}

\section{A}
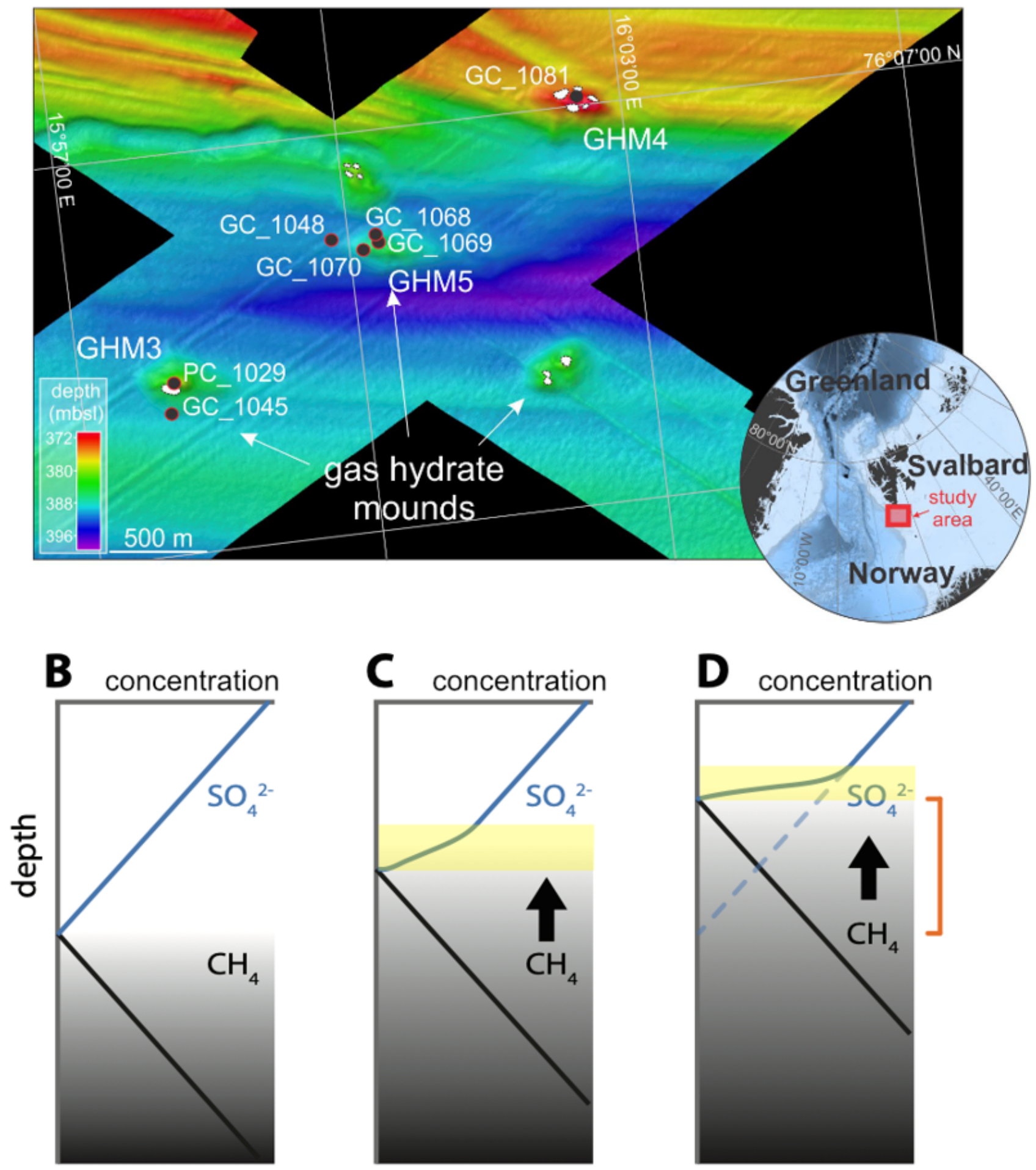

Figure 1 
Bathymetric map of Storfjordrenna gas hydrate mounds and modeling approach. (A) Storfjordrenna is located south of the Svalbard Archipelago. Locations of gravity cores (GCs), push core (PC), and gas hydrate mounds (GHMs) are shown. White polygons indicate areas of seafloor gas release observed at the time of the cruise in 2016. All cores were collected from GHMs, with the exception of GC1048, which was sampled west of GHM5, 155 m away from GC1070 and over 200 m away from GC1068 and GC1069. The schematic in (B) depicts sulfate and methane concentrations throughout a sediment column at a steady-state condition. As methane flux increases, (C), SR-AOM is stimulated at shallower depths and sulfate profiles show a concave-up curvature. After decades of steadily increasing methane flux at a particular area, (D), reactive-transport modeling can be used to estimate how quickly the methane front diffused the distance between the current and prior sulfate depletion depths (indicated by the orange bracket). 


\section{A}
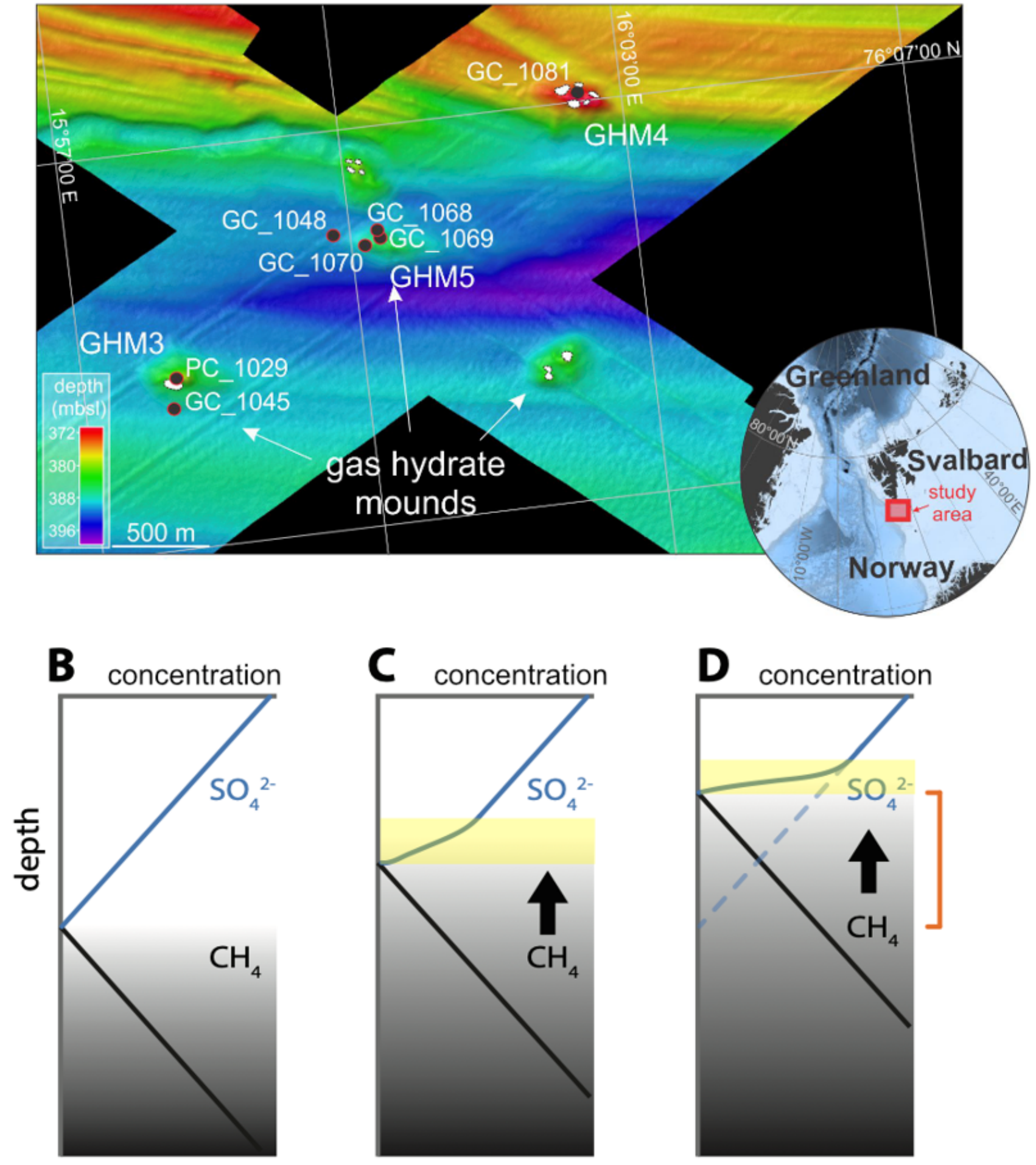

\section{Figure 1}

Bathymetric map of Storfjordrenna gas hydrate mounds and modeling approach. (A) Storfjordrenna is located south of the Svalbard Archipelago. Locations of gravity cores (GCs), push core (PC), and gas hydrate mounds (GHMs) are shown. White polygons indicate areas of seafloor gas release observed at the time of the cruise in 2016. All cores were collected from GHMs, with the exception of GC1048, which was sampled west of GHM5, 155 m away from GC1070 and over 200 m away from GC1068 and 
GC1069. The schematic in (B) depicts sulfate and methane concentrations throughout a sediment column at a steady-state condition. As methane flux increases, (C), SR-AOM is stimulated at shallower depths and sulfate profiles show a concave-up curvature. After decades of steadily increasing methane flux at a particular area, (D), reactive-transport modeling can be used to estimate how quickly the methane front diffused the distance between the current and prior sulfate depletion depths (indicated by the orange bracket).

$\boldsymbol{A}$

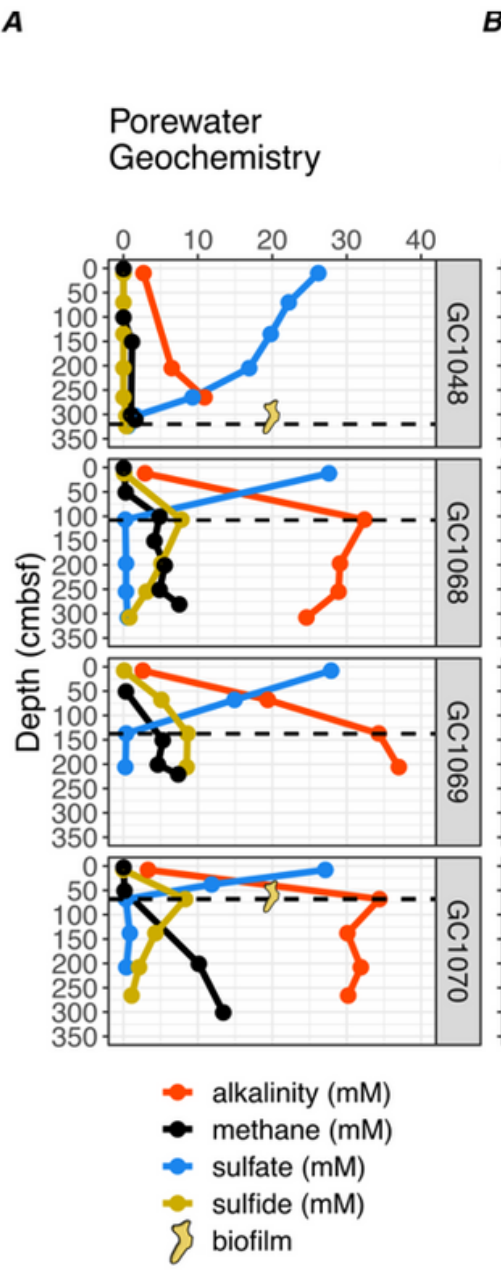

B

AOM rate $\left(\mathrm{nmol} \mathrm{cm}^{-3} \mathrm{~d}^{-1}\right)$

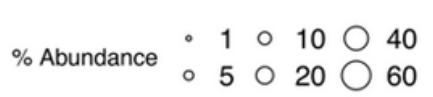

- Archaea - Bacteria
$\boldsymbol{D}$

$\log _{10}$ gene copies gene $\approx \mathrm{mcrA} \approx \mathrm{dsr} A \mathrm{~B}$

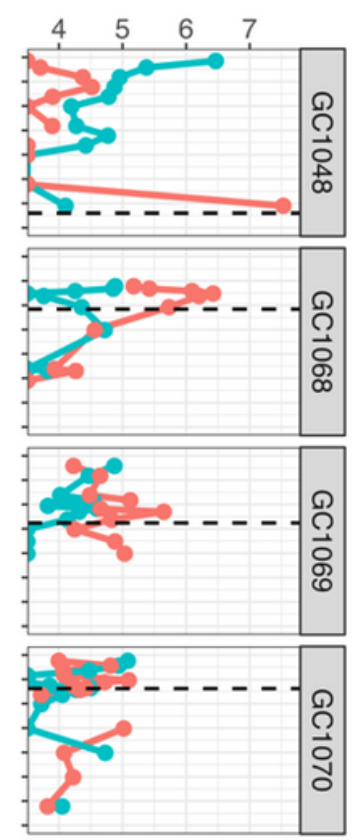

\section{Figure 2}

Geochemical, numerical, microbial community, and gene abundance data from four sites showing steady-state sulfate-methane dynamics. GC1068-1070 are from GHM5, and GC1048 is located to the west of GHM5. SMT depths are indicated by dashed lines. (A) shows methane concentrations and porewater sulfate, sulfide, and alkalinity, and (B) present-day modeled AOM rates. (C) indicates percent abundances of dominant bacterial and archaeal classes, dominant anaerobic methanotrophic archaeal (ANME) families, and sulfate-reducing bacterial (SRB) genera. (D) shows copy numbers of mcrA and dsrAB genes per gram bulk sediment, with values below the detectable limit (103 g-1) along the margin of the panel. Macroscopic translucent-to-yellow biofilms, shown as yellow symbols in panel (A), were observed at approximate SMT depths in cores GC1048 and GC1070 (symbol size not to scale with depth axis). 
A

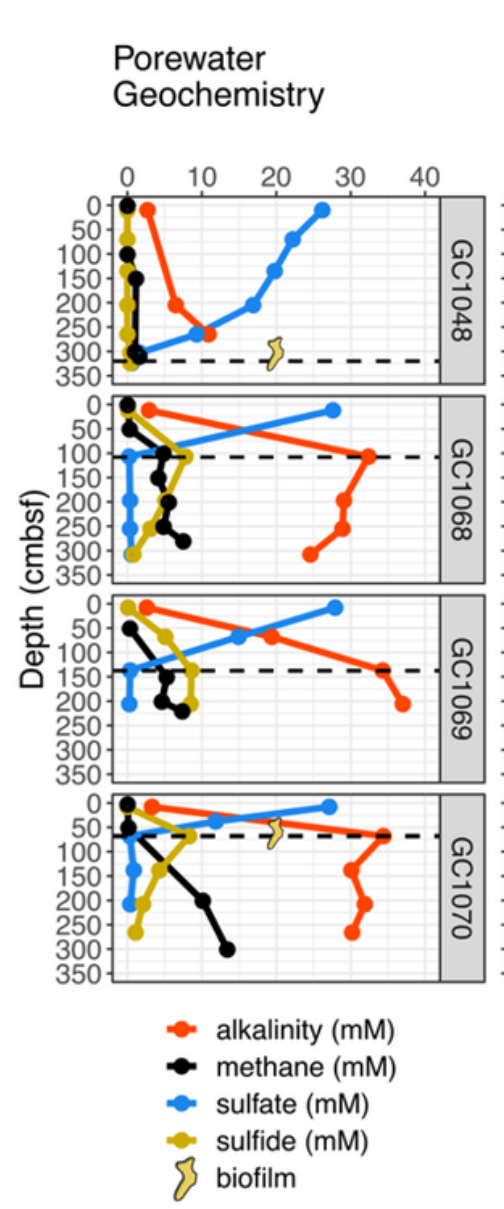

C

$\%$ Abundance $\odot 1$ - $1010 \bigcirc 40$

AOM rate $\left(\mathrm{nmol} \mathrm{cm} \mathrm{c}^{-3}\right) \quad$ - Archaea - Bacteria
$\boldsymbol{D}$

$\log _{10}$ gene copies

gene $\approx$ mcrA $\approx$ dsrAB

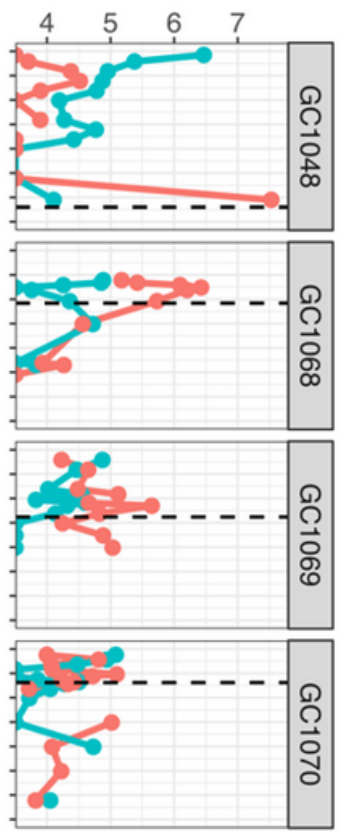

Figure 2

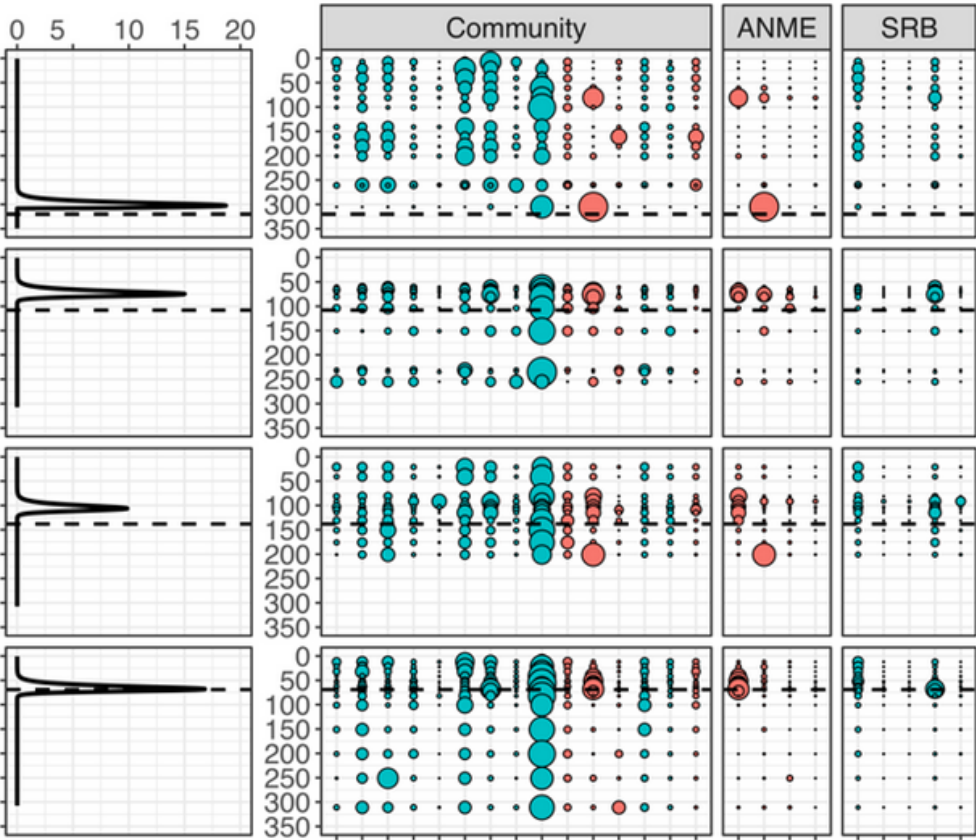

Geochemical, numerical, microbial community, and gene abundance data from four sites showing steady-state sulfate-methane dynamics. GC1068-1070 are from GHM5, and GC1048 is located to the west of GHM5. SMT depths are indicated by dashed lines. (A) shows methane concentrations and porewater sulfate, sulfide, and alkalinity, and (B) present-day modeled AOM rates. (C) indicates percent abundances of dominant bacterial and archaeal classes, dominant anaerobic methanotrophic archaeal (ANME) families, and sulfate-reducing bacterial (SRB) genera. (D) shows copy numbers of mcrA and dsrAB genes per gram bulk sediment, with values below the detectable limit (103 g-1) along the margin of the panel. Macroscopic translucent-to-yellow biofilms, shown as yellow symbols in panel (A), were observed at approximate SMT depths in cores GC1048 and GC1070 (symbol size not to scale with depth axis). 


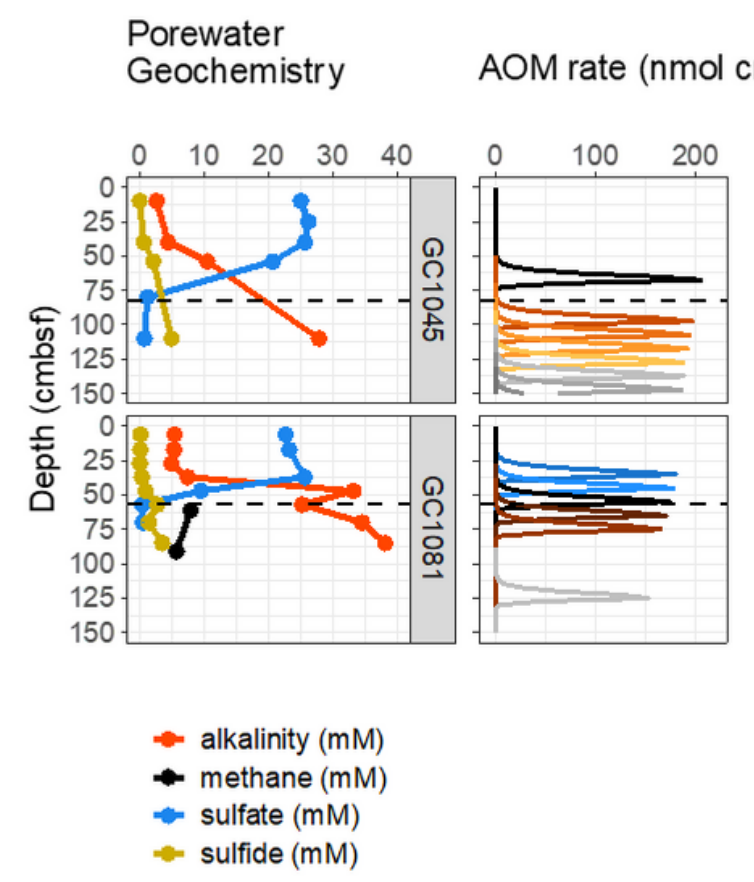

$$
\text { AOM rate }\left(\mathrm{nmol} \mathrm{cm} \mathrm{cm}^{-3} \mathrm{~d}^{-1}\right)
$$$$
\% \text { Abundance } \cdot 1 \odot 5 \bigcirc 10 \bigcirc 20 \bigcirc 40
$$$$
\text { - mcra }- \text { dsrab }
$$
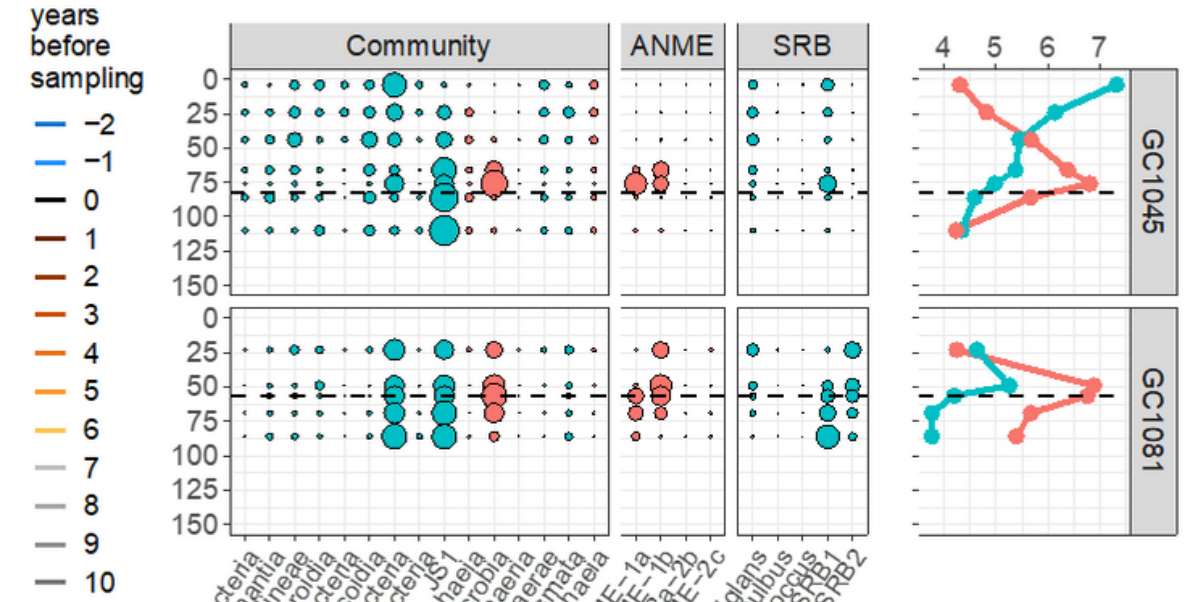

\section{Figure 3}

Geochemical, numerical, microbial community, and gene abundance data from two sites showing sulfatemethane dynamics suggestive of recent increases in methane flux. Gravity cores GC1045 and GC1081 are located at GHMs 3 and 4, respectively. SMT depths are indicated by dashed lines. (A) shows methane concentrations and porewater sulfate, sulfide, and alkalinity, and (B) the temporal progression of modeled AOM rates from 10 years ago to up to 2 years after sampling. (C) indicates percent abundances of dominant bacterial and archaeal classes, dominant anaerobic methanotrophic archaeal (ANME) families, and sulfate-reducing bacterial (SRB) genera. (D) shows copy numbers of mcrA and dsrAB genes per gram bulk sediment. 


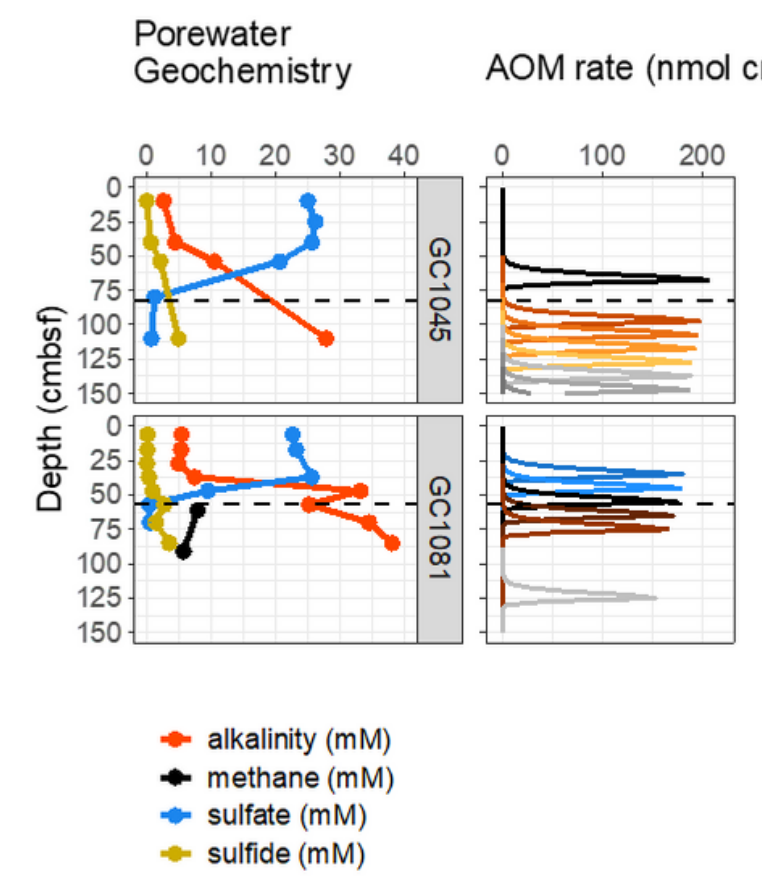

$$
\text { AOM rate }\left(\mathrm{nmol} \mathrm{cm} \mathrm{cm}^{-3} \mathrm{~d}^{-1}\right)
$$$$
\% \text { Abundance } \cdot 1 \odot 5 \circ 10 \bigcirc 20 \bigcirc 40
$$$$
\text { - mcra - dsrab }
$$
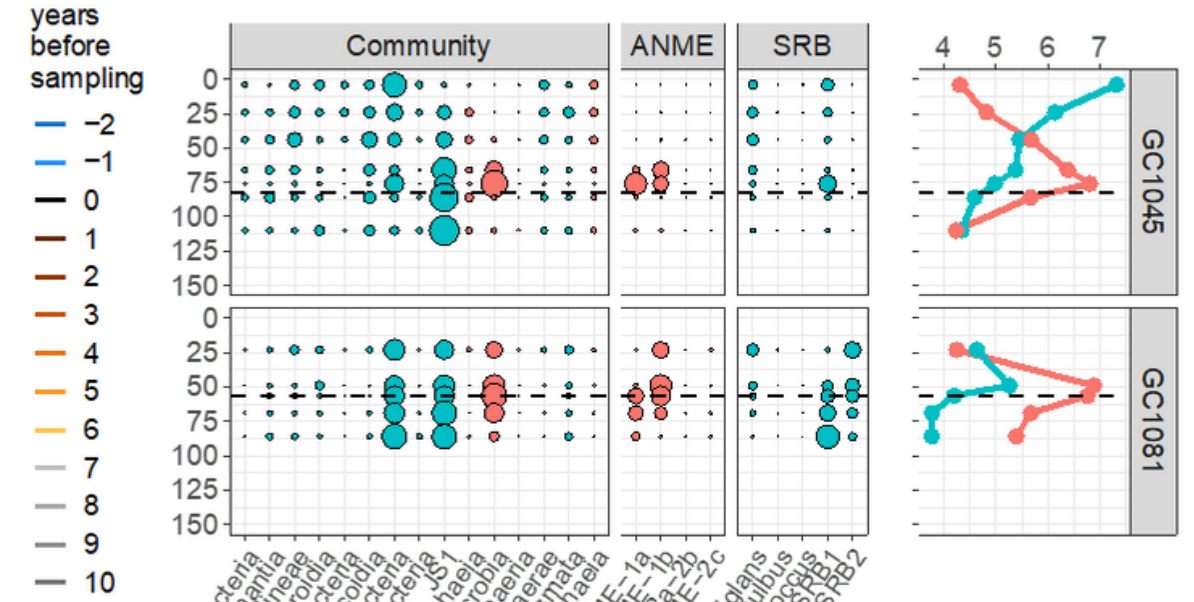

\section{Figure 3}

Geochemical, numerical, microbial community, and gene abundance data from two sites showing sulfatemethane dynamics suggestive of recent increases in methane flux. Gravity cores GC1045 and GC1081 are located at GHMs 3 and 4, respectively. SMT depths are indicated by dashed lines. (A) shows methane concentrations and porewater sulfate, sulfide, and alkalinity, and (B) the temporal progression of modeled AOM rates from 10 years ago to up to 2 years after sampling. (C) indicates percent abundances of dominant bacterial and archaeal classes, dominant anaerobic methanotrophic archaeal (ANME) families, and sulfate-reducing bacterial (SRB) genera. (D) shows copy numbers of mcrA and dsrAB genes per gram bulk sediment. 

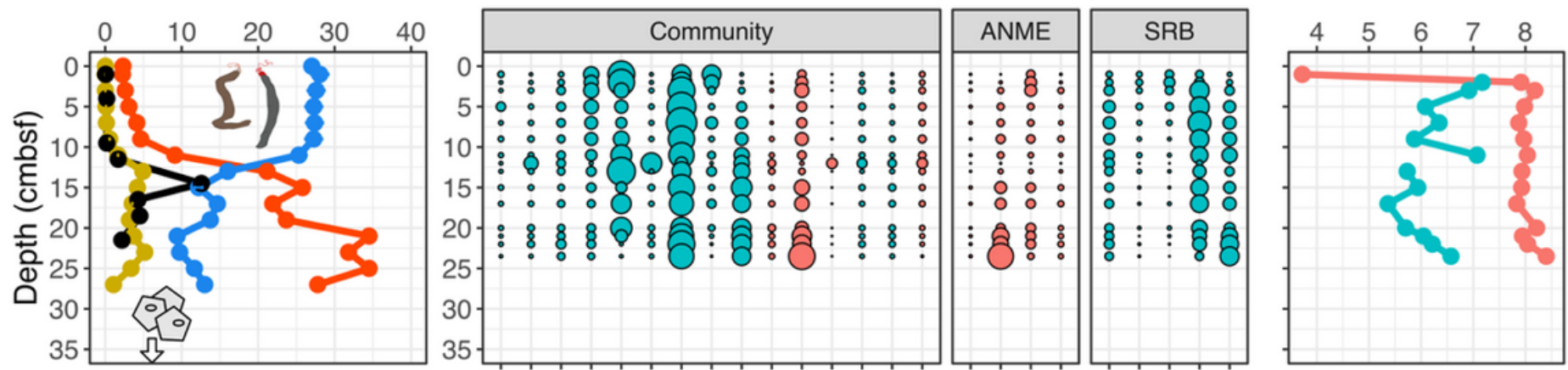

alkalinity (mM)

- methane (mM)

$\sim$ sulfate (mM)

sulfide (mM)

2) tubeworms

盛 gas hydrates

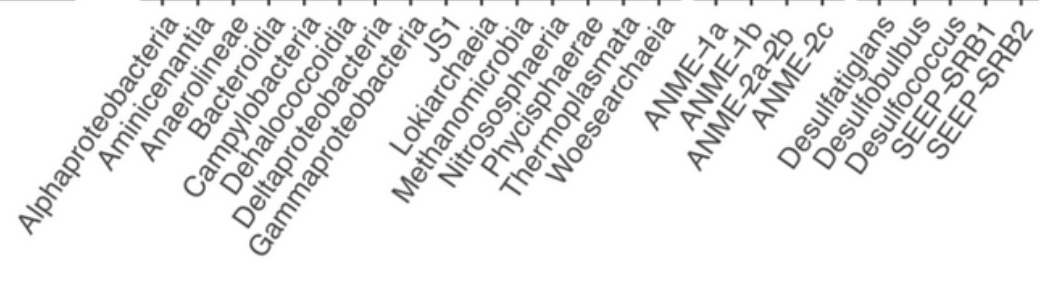

\section{Figure 4}

Geochemical, microbial community, and gene abundance data from an active seep site. Push core PC1029 is located at the seep in the center of GHM3. (A) shows methane concentrations and porewater sulfate, sulfide, and alkalinity concentrations in addition to frenulate siboglinids and gas hydrate nodules several $\mathrm{cm}$ in diameter recovered in a replicate core at 40-50 cm below seafloor. Sulfate concentrations are shown with $4 \%$ error bars. (B) depicts percent abundances of dominant bacterial and archaeal classes within the microbial community (left panel), dominant anaerobic methanotrophic archaeal (ANME) families (center panel) and sulfate-reducing bacterial (SRB) genera (right panel). (C) shows log10 copy numbers of mcrA and dsrAB genes per gram bulk sediment. 

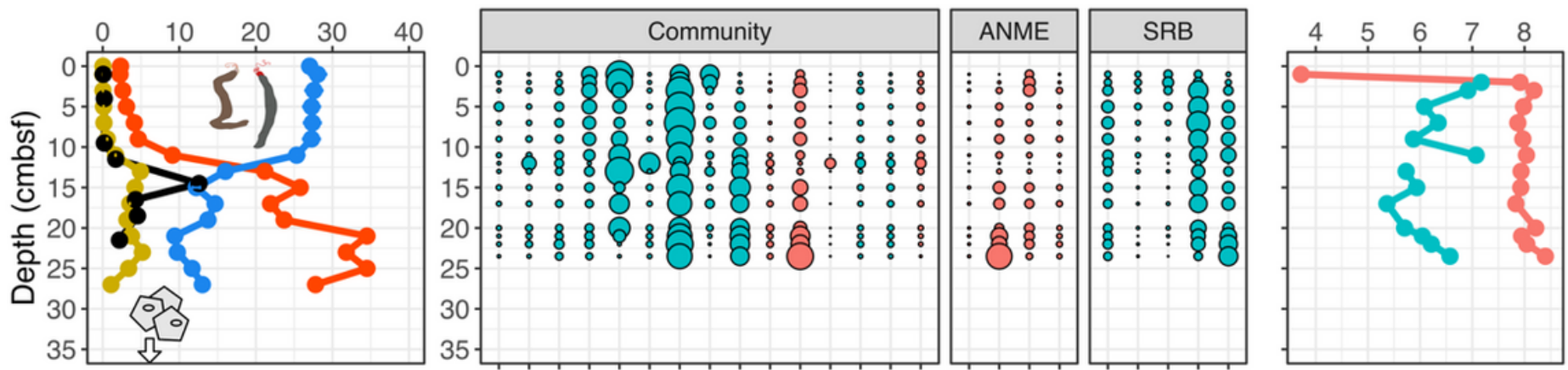

alkalinity (mM)

- methane (mM)

$\sim$ sulfate (mM)

sulfide (mM)

2) tubeworms

盛 gas hydrates

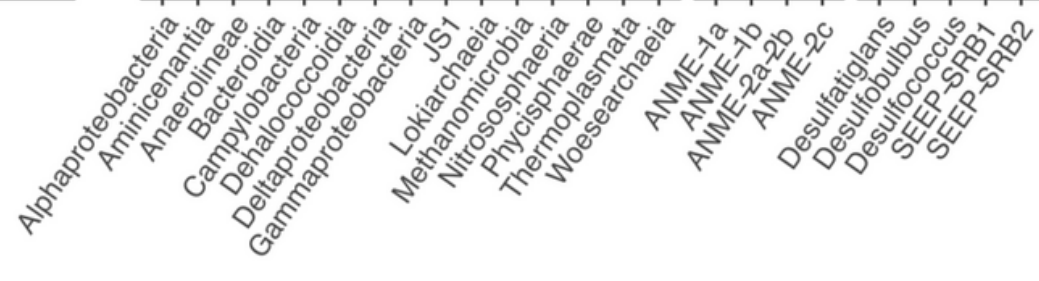

\section{Figure 4}

Geochemical, microbial community, and gene abundance data from an active seep site. Push core PC1029 is located at the seep in the center of GHM3. (A) shows methane concentrations and porewater sulfate, sulfide, and alkalinity concentrations in addition to frenulate siboglinids and gas hydrate nodules several $\mathrm{cm}$ in diameter recovered in a replicate core at 40-50 cm below seafloor. Sulfate concentrations are shown with $4 \%$ error bars. (B) depicts percent abundances of dominant bacterial and archaeal classes within the microbial community (left panel), dominant anaerobic methanotrophic archaeal (ANME) families (center panel) and sulfate-reducing bacterial (SRB) genera (right panel). (C) shows log10 copy numbers of mcrA and dsrAB genes per gram bulk sediment. 


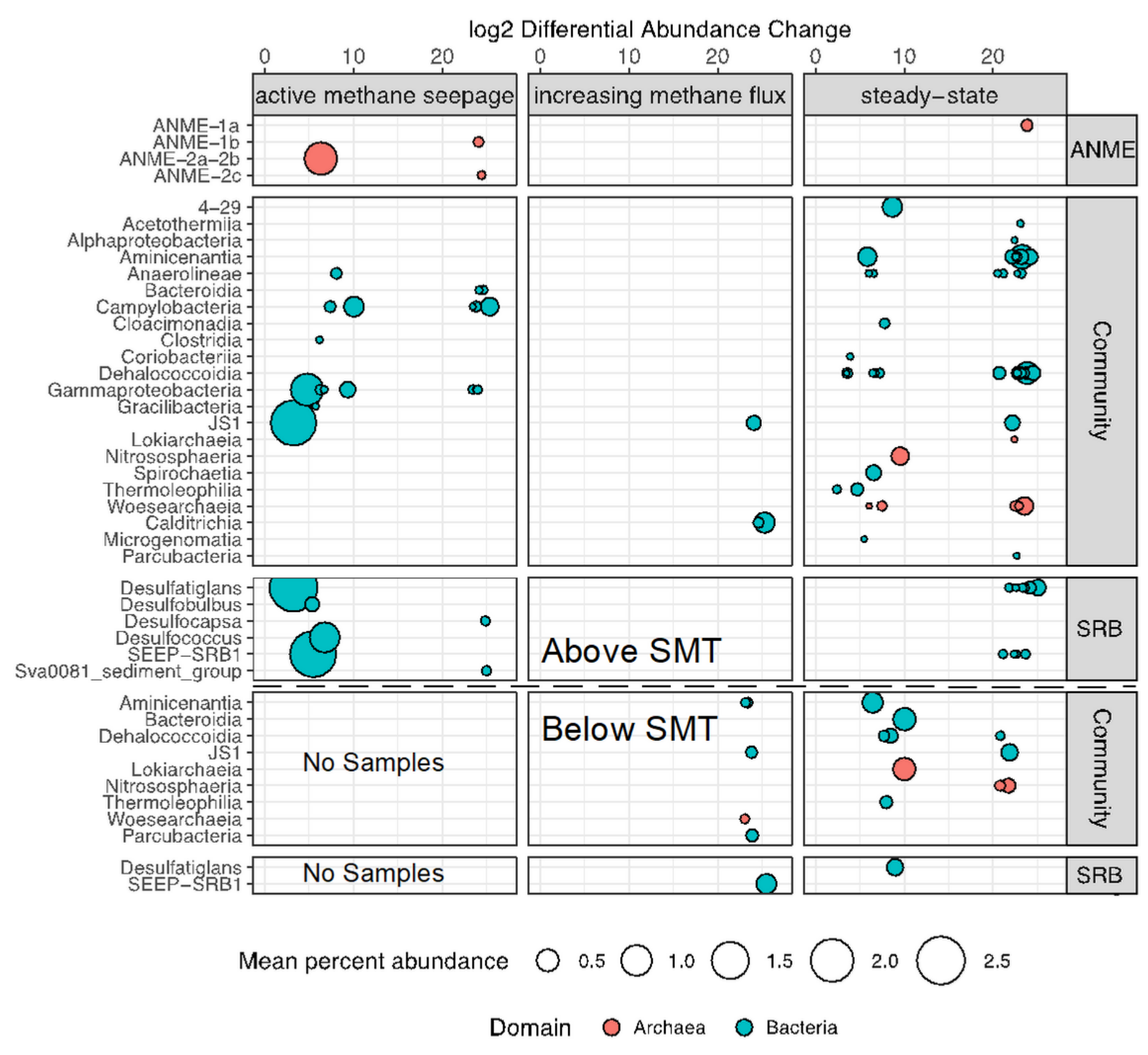

\section{Figure 5}

Differentially abundant ASVs identified across three regimes of methane dynamics, either above or below the sulfate-methane transition (SMT) zone (indicated by dashed line). Higher differential abundance values (top axis) represent stronger statistical associations between an ASV and a particular group. In addition to position relative to the SMT, vertical panels convey class-level taxonomic annotations for all taxa except ANME (at family level) and SRB (at genus level). Bubble sizes represent mean percent abundances within each group. Differential abundance was inferred using an alpha of 0.05 and a Benjamini-Hochberg correction for multiple comparisons. 


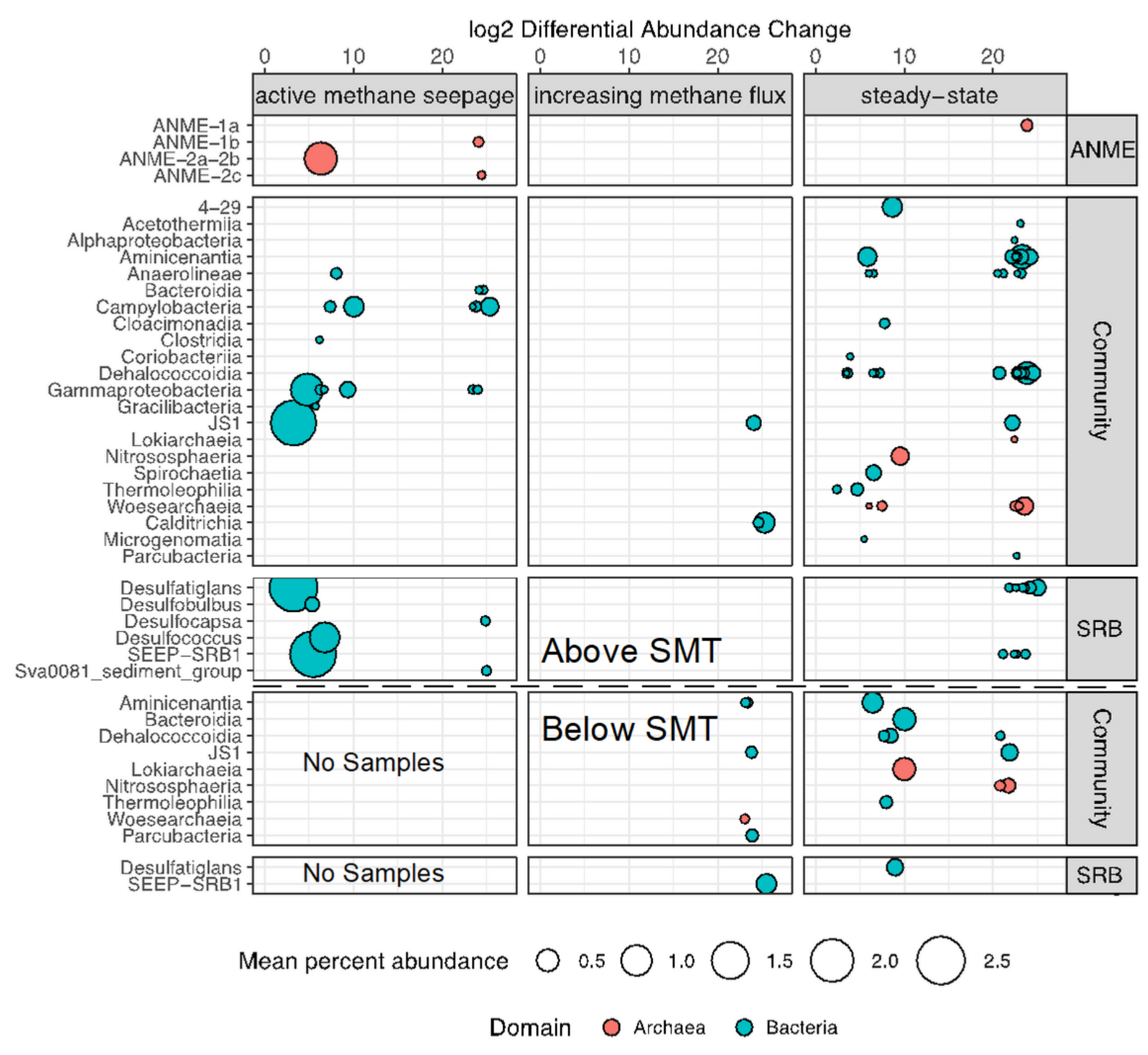

\section{Figure 5}

Differentially abundant ASVs identified across three regimes of methane dynamics, either above or below the sulfate-methane transition (SMT) zone (indicated by dashed line). Higher differential abundance values (top axis) represent stronger statistical associations between an ASV and a particular group. In addition to position relative to the SMT, vertical panels convey class-level taxonomic annotations for all taxa except ANME (at family level) and SRB (at genus level). Bubble sizes represent mean percent abundances within each group. Differential abundance was inferred using an alpha of 0.05 and a Benjamini-Hochberg correction for multiple comparisons. 


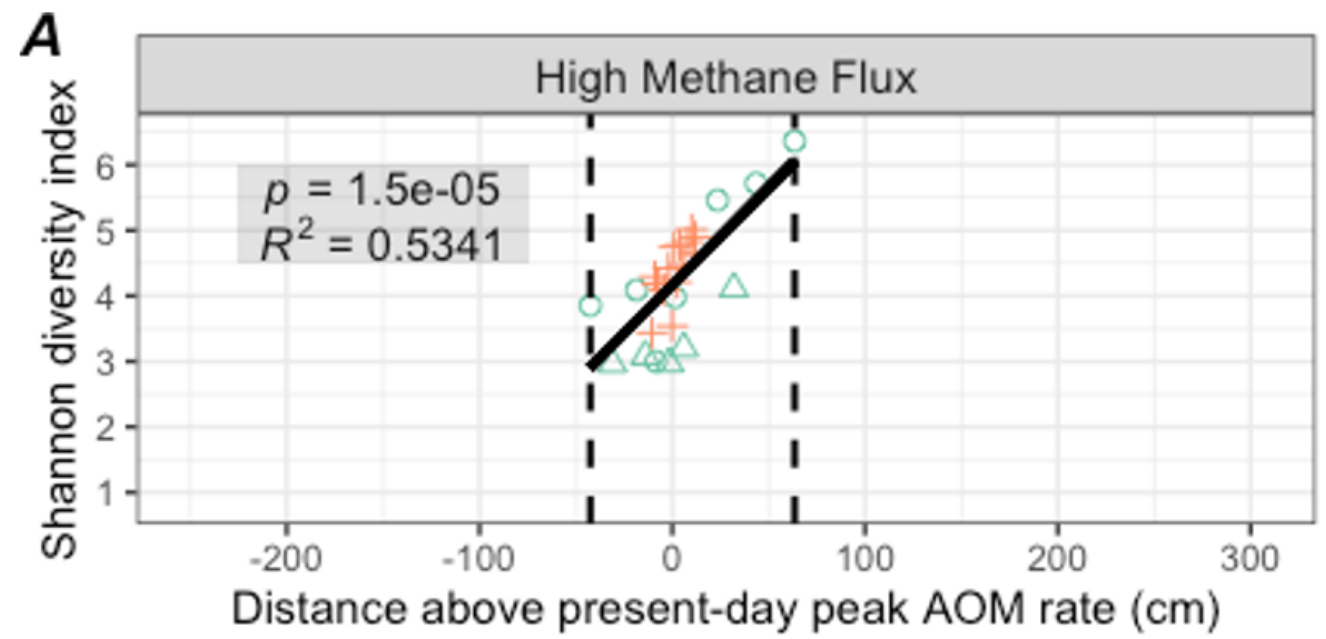

Methane regime

- active methane seepage

- increasing methane flux

Core

- GC1045

$\triangle$ GC1081

+ PC1029

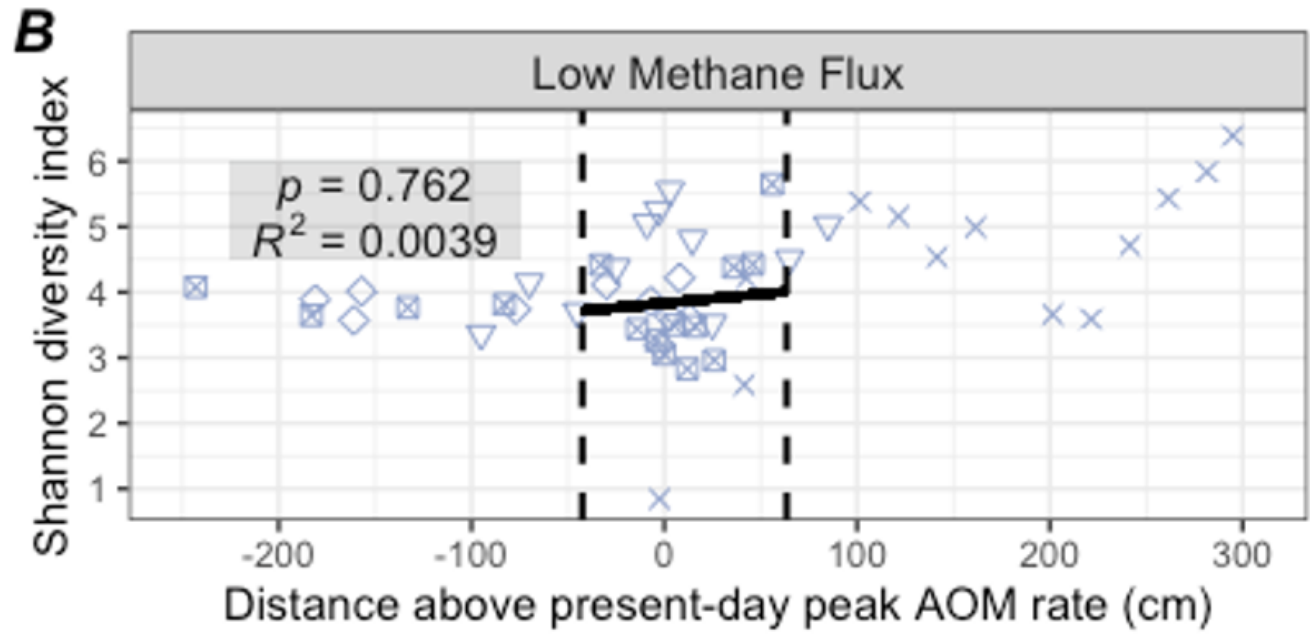

Core

$\times \quad$ GC1048

$\diamond$ GC1068

$\nabla \quad$ GC1069

凶 GC1070

Methane regime

- steady-state

Figure 6

Microbial community diversity patterns across peak modeled AOM depths. Shannon diversity indices of microbial communities for individual samples plotted by their distance above (positive) or below (negative) the depths corresponding to present-day maximum AOM rates across all cores. Cores are divided by panel based on whether methane flux is (A) high, or (B) low, and colored according to different regimes of methane dynamics. Dashed vertical lines show the distance interval corresponding to high methane flux samples. Multiple R2 and slope p-values are shown for linear regressions of points within these intervals. 


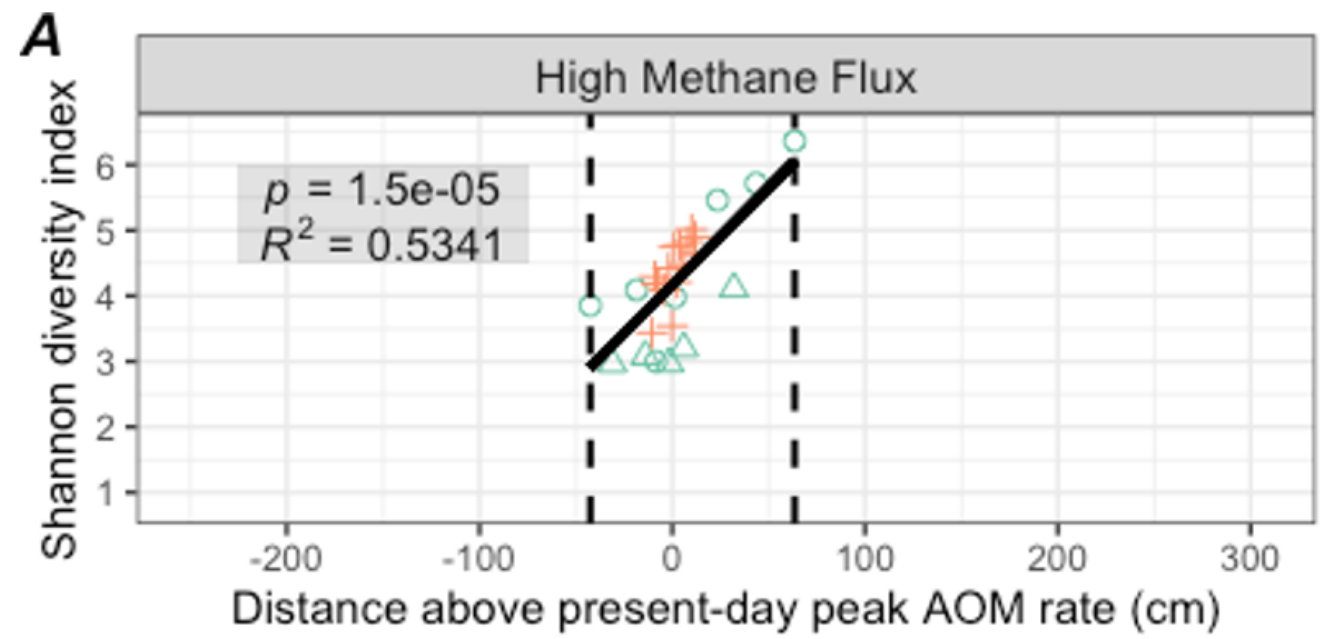

Methane regime

- active methane seepage

- increasing methane flux

Core

- GC1045

$\triangle$ GC1081

+ PC1029

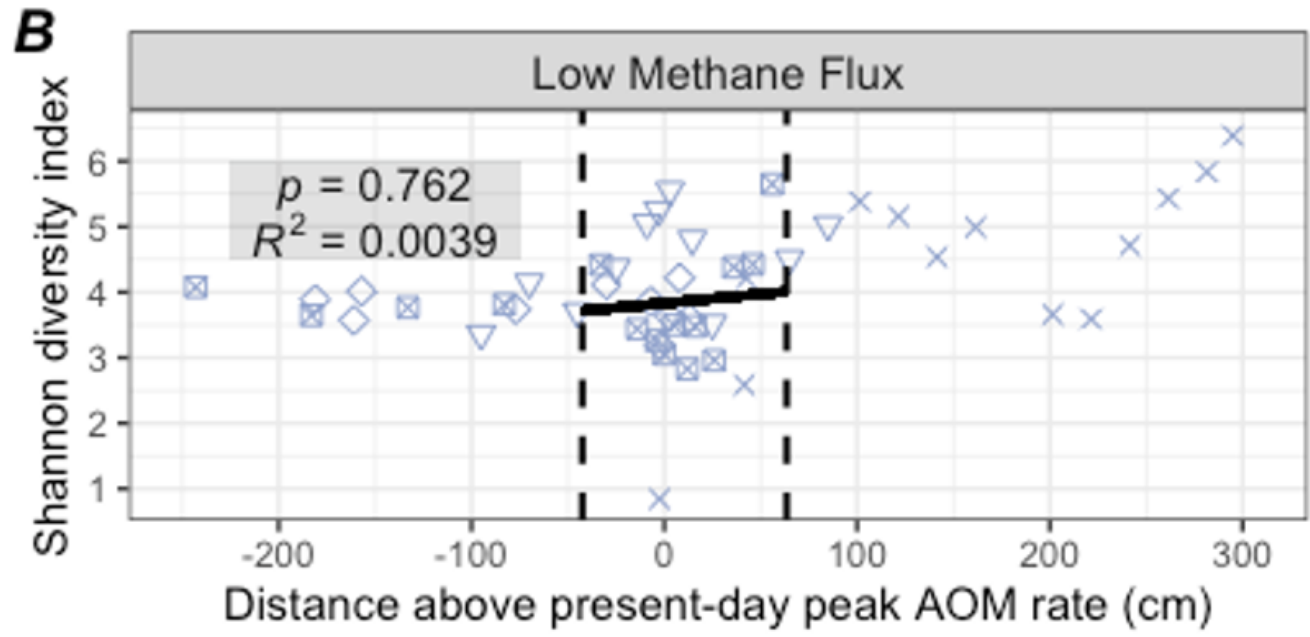

Core

$\times \quad$ GC1048

$\diamond$ GC1068

$\nabla \quad$ GC1069

凶 GC1070

Methane regime

- steady-state

Figure 6

Microbial community diversity patterns across peak modeled AOM depths. Shannon diversity indices of microbial communities for individual samples plotted by their distance above (positive) or below (negative) the depths corresponding to present-day maximum AOM rates across all cores. Cores are divided by panel based on whether methane flux is (A) high, or (B) low, and colored according to different regimes of methane dynamics. Dashed vertical lines show the distance interval corresponding to high methane flux samples. Multiple R2 and slope p-values are shown for linear regressions of points within these intervals. 


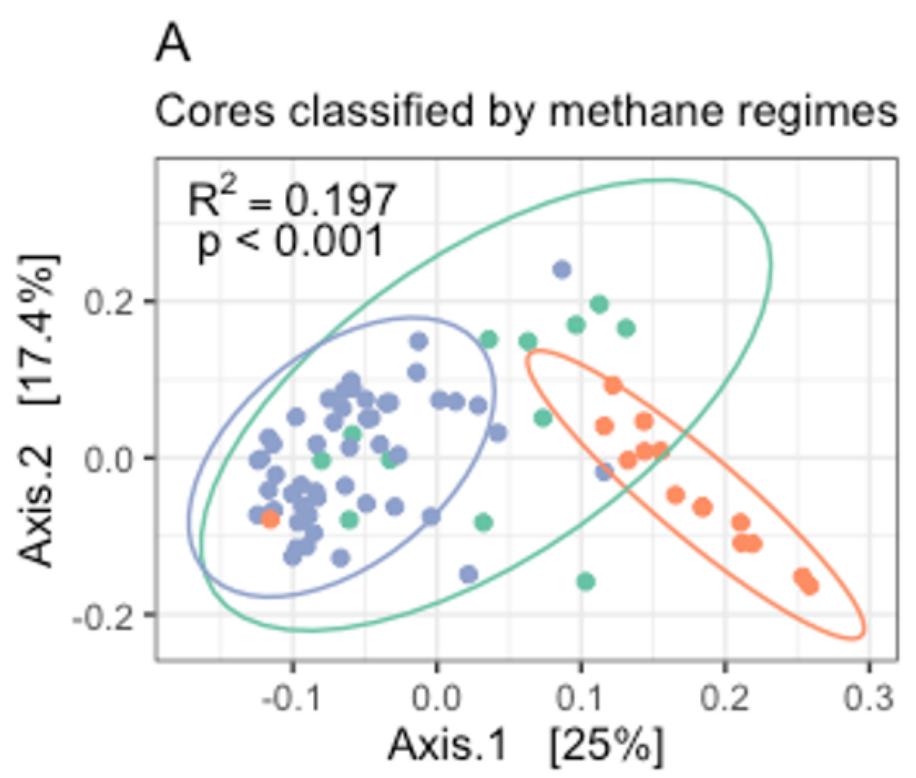

- active methane seepage
- increasing methane flux
- steady-state
B

Samples classified by redox zones

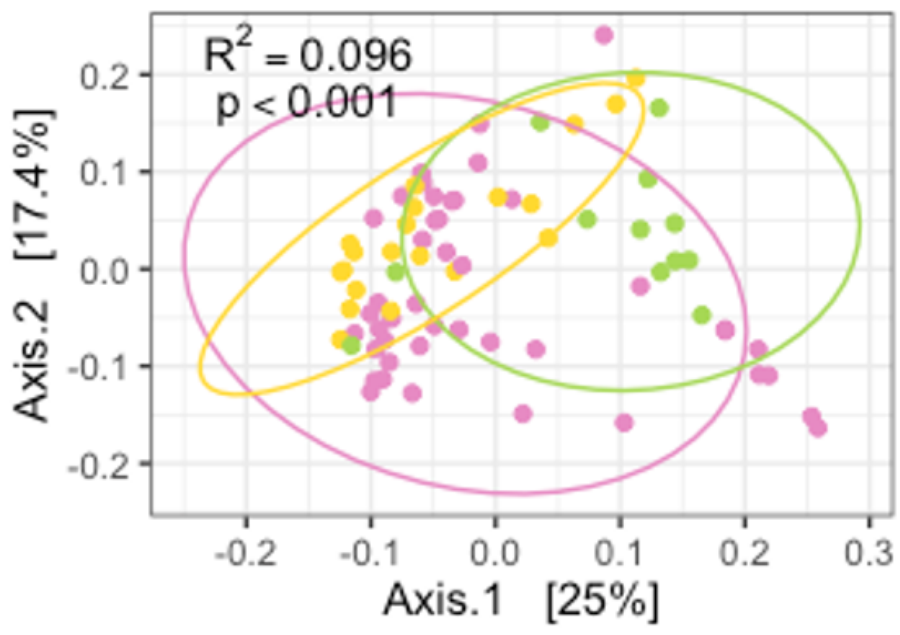

- linear SR zone
- nonlinear SR zone
- below SMT

\section{Figure 7}

Principal Coordinates Analysis (PCOA) ordination of weighted Unifrac distances between all communities, colored according to regimes of methane dynamics (A), and redox zones within the sediment column (B). A Hellinger transformation was applied to ASV count tables before calculating the distance matrix. PERMANOVA tests verify distinct community structures present across regimes and redox zones, with R2 and p-values shown in corresponding plots. 


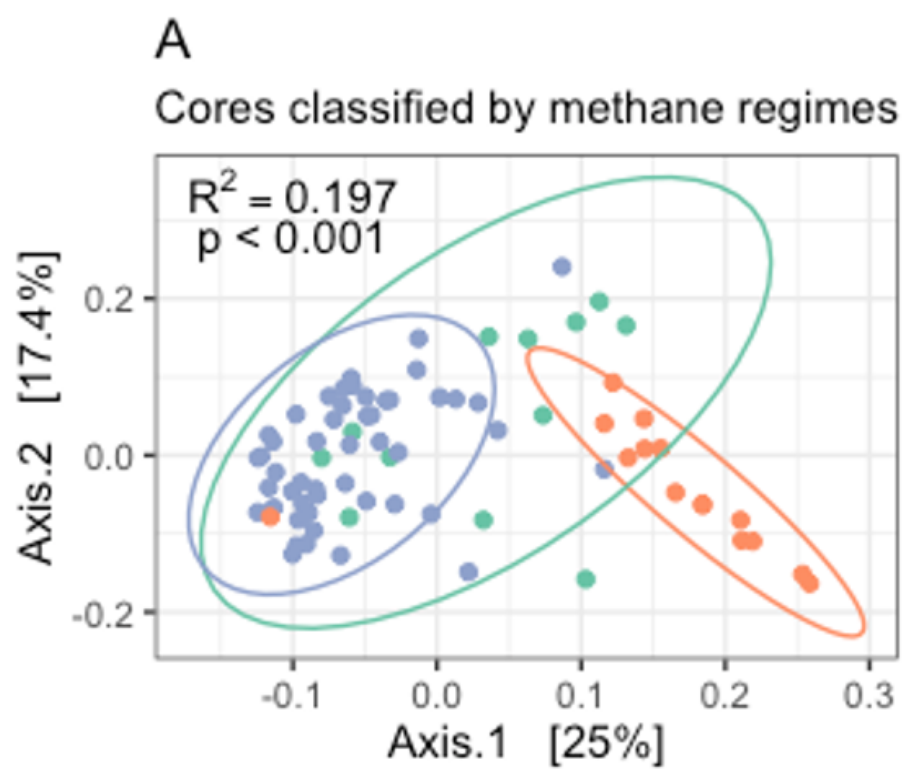

- active methane seepage

- increasing methane flux

- steady-state
B

Samples classified by redox zones
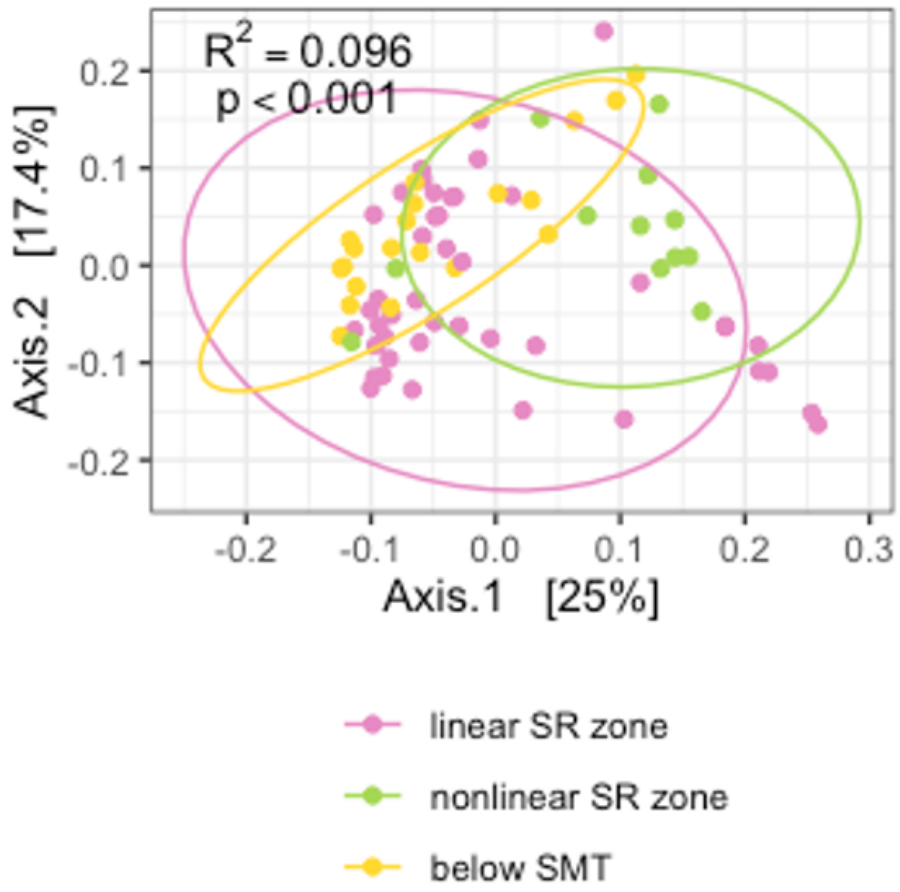

\section{Figure 7}

Principal Coordinates Analysis (PCoA) ordination of weighted Unifrac distances between all communities, colored according to regimes of methane dynamics (A), and redox zones within the sediment column (B). A Hellinger transformation was applied to ASV count tables before calculating the distance matrix. PERMANOVA tests verify distinct community structures present across regimes and redox zones, with R2 and p-values shown in corresponding plots. 
A

Steady-state biogeochemical equilibrium GCs $1048,1068-1070$
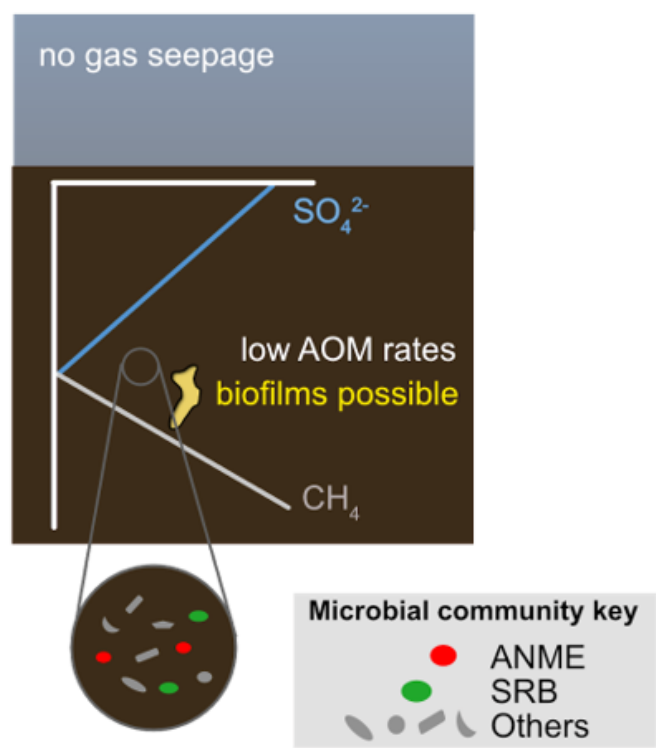

B

Increasing methane flux GCs 1045, 1081

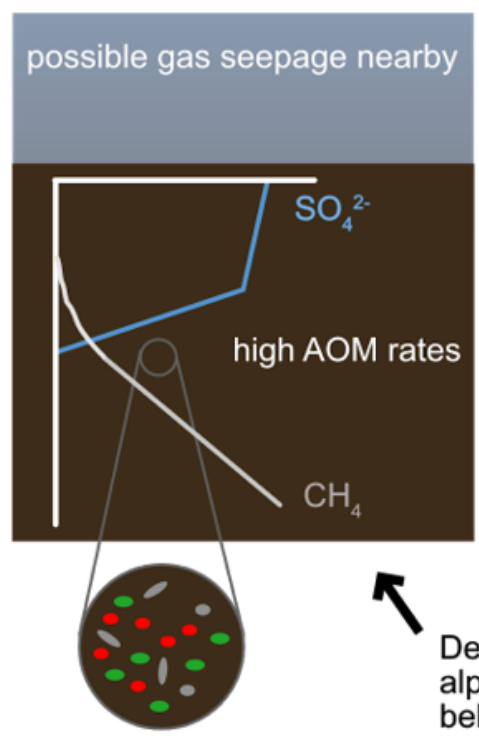

C

Active methane seepage PC1029

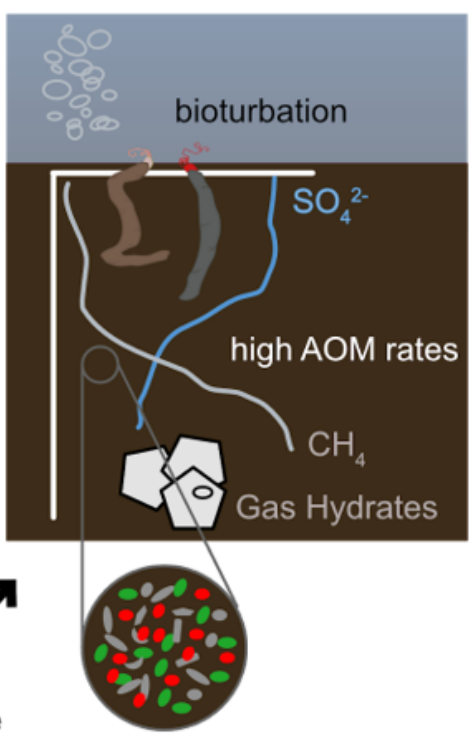

\section{Figure 8}

Conceptual depiction of microbial community changes concurrent with distinct regimes of methane dynamics at Storfjordrenna GHMs. Panels A, B, and C illustrate data shown in Figures 2, 3 and 4, respectively. Methane and sulfate profiles are shown in gray and blue lines, respectively, with microbial community changes indicated by blowup circles. ANME and SRB represent red and green ovals, with other bacteria and archaea in gray (shapes representing the diversity of other taxa). (A) Steady-state sulfate profiles suggest a weak methane influx, and low rates of AOM are observed at the SMT. Stable conditions may allow for higher microbial diversity in sediment communities and the growth of macroscopic biofilms. (B) A concave-up bend in porewater sulfate suggests recent methane migration into the sulfate-reduction zone consistent with a pulse of methane beginning hundreds of years ago (approx. 290 years ago at GC1045). Methane travels upward throughout the sediment column, and ANME/SRB growth follows with less than a year of lag time, driving down alpha diversity. (C) Methane seepage stimulates high rates of AOM and densities of ANME/SRB. Sulfide fluxes from AOM-coupled sulfate reduction are sufficient to support frenulate siboglinids, which may distribute sulfate across the upper several $\mathrm{cm}$ of sediment, increase redox gradients in underlying sediments, and further ANME/SRB growth. 
Steady-state biogeochemical equilibrium GCs 1048, 1068-1070

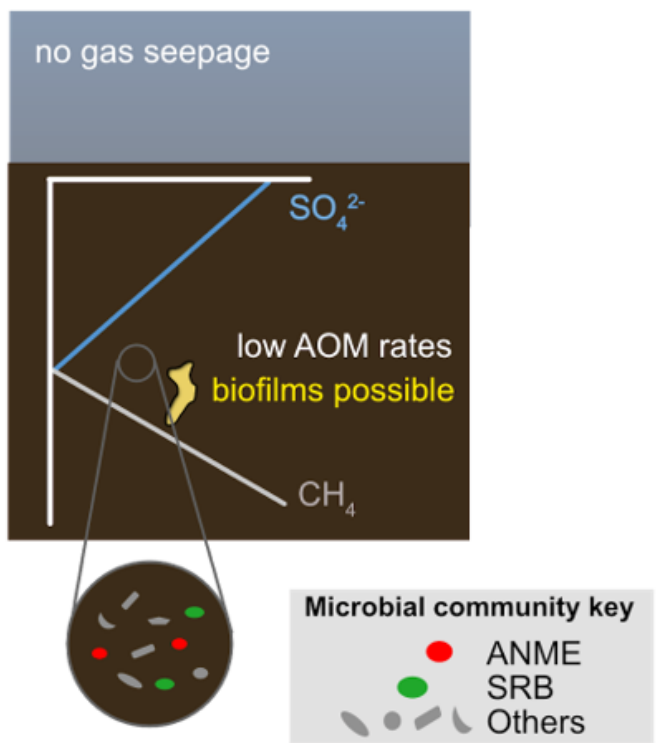

B

Increasing methane flux GCs 1045,1081

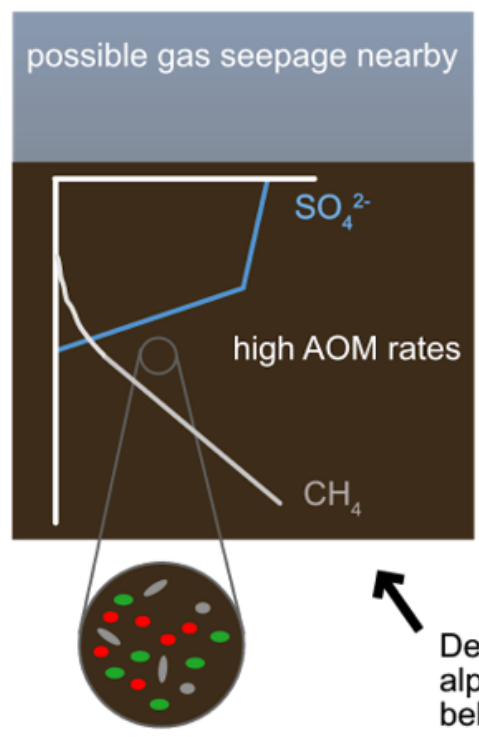

C

Active methane seepage PC1029

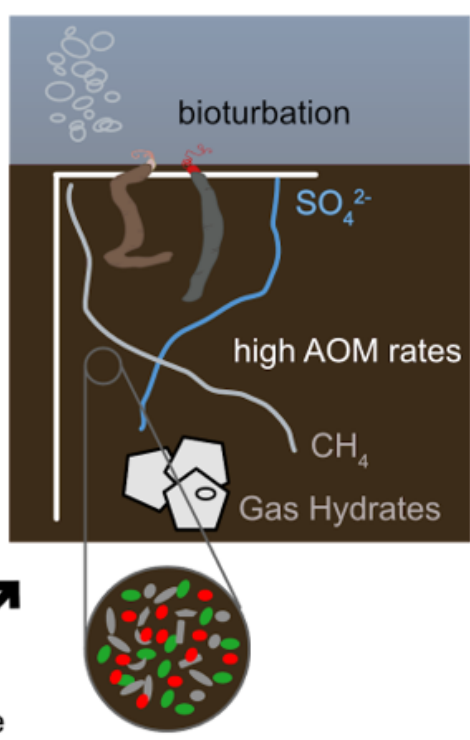

\section{Figure 8}

Conceptual depiction of microbial community changes concurrent with distinct regimes of methane dynamics at Storfjordrenna GHMs. Panels A, B, and C illustrate data shown in Figures 2, 3 and 4, respectively. Methane and sulfate profiles are shown in gray and blue lines, respectively, with microbial community changes indicated by blowup circles. ANME and SRB represent red and green ovals, with other bacteria and archaea in gray (shapes representing the diversity of other taxa). (A) Steady-state sulfate profiles suggest a weak methane influx, and low rates of AOM are observed at the SMT. Stable conditions may allow for higher microbial diversity in sediment communities and the growth of macroscopic biofilms. (B) A concave-up bend in porewater sulfate suggests recent methane migration into the sulfate-reduction zone consistent with a pulse of methane beginning hundreds of years ago (approx. 290 years ago at GC1045). Methane travels upward throughout the sediment column, and ANME/SRB growth follows with less than a year of lag time, driving down alpha diversity. (C) Methane seepage stimulates high rates of AOM and densities of ANME/SRB. Sulfide fluxes from AOM-coupled sulfate reduction are sufficient to support frenulate siboglinids, which may distribute sulfate across the upper several $\mathrm{cm}$ of sediment, increase redox gradients in underlying sediments, and further ANME/SRB growth.

\section{Supplementary Files}

This is a list of supplementary files associated with this preprint. Click to download.

- SupplementalsKlaseksvalflux.pdf 
- SupplementalsKlaseksvalflux.pdf

- Tables2.xIsx

- Tables2.xlsx 